\title{
Problems, assumptions and solutions in locomotive design, traction and operational studies
}

\author{
Maksym Spiryagin $^{1} \cdot$ Qing Wu ${ }^{1} \cdot$ Oldrich Polach $^{2} \cdot$ John Thorburn ${ }^{3} \cdot$ \\ Wenhsi Chua $^{4} \cdot$ Valentyn Spiryagin $^{5} \cdot$ Sebastian Stichel $^{6} \cdot$ Sundar Shrestha $^{1}$. \\ Esteban Bernal $^{1} \cdot$ Sanjar Ahmad $^{1} \cdot$ Colin Cole $^{1} \cdot$ Tim McSweeney $^{1}$
}

Received: 17 June 2021 / Revised: 20 October 2021 / Accepted: 24 October 2021 / Published online: 8 January 2022

(C) The Author(s) 2022

\begin{abstract}
Locomotive design is a highly complex task that requires the use of systems engineering that depends upon knowledge from a range of disciplines and is strongly oriented on how to design and manage complex systems that operate under a wide range of different train operational conditions on various types of tracks. Considering that field investigation programs for locomotive operational scenarios involve high costs and cause disruption of train operations on real railway networks and given recent developments in the rollingstock compliance standards in Australia and overseas that allow the assessment of some aspects of rail vehicle behaviour through computer simulations, a great number of multidisciplinary research studies have been performed and these can contribute to further improvement of a locomotive design technique by increasing the amount of computer-based studies. This paper was focused on the presentation of the all-important key components required for locomotive studies, starting from developing a realistic locomotive design model, its validation and further applications for train studies. The integration of all engineering disciplines is achieved by
\end{abstract}

Maksym Spiryagin

m.spiryagin@cqu.edu.au

1 Centre for Railway Engineering, Central Queensland University, Rockhampton 4702, Australia

2 Independent Consultant, Neuhausen am Rheinfall, Switzerland

3 Progress Rail, Newcastle, Australia

4 BHP, Port Hedland, Australia

5 Engineering Centre for Railway Transport, Skolkovo, Russian Federation

6 KTH Royal Institute of Technology, Stockholm, Sweden means of advanced simulation approaches that can incorporate existing AC and DC locomotive designs, hybrid locomotive designs, full locomotive traction system models, rail friction processes, the application of simplified and exact wheel-rail contact theories, wheel-rail wear and rolling contact fatigue, train dynamic behaviour and intrain forces, comprehensive track infrastructure details, and the use of co-simulation and parallel computing. The cosimulation and parallel computing approaches that have been implemented on Central Queensland University's High-Performance Computing cluster for locomotive studies will be presented. The confidence in these approaches is based on specific validation procedures that include a locomotive model acceptance procedure and field test data. The problems and limitations presented in locomotive traction studies in the way they are conducted at the present time are summarised and discussed.

Keywords Locomotive · Design - Simulation · Virtual prototyping · Digital twin · Traction · Braking · Wheel-rail wear · Damage

\section{Introduction}

The development process of modern locomotives has significantly changed during the last 20 years. Originally, the design principles were based on a so-called standard locomotive product approach as shown in Fig. 1. In other words, it can be classified with the following sequential stages as engineering-manufacturing-testing-commissioning-supply. Originally, the design specification was a 
highly specific and quite detailed document [1] that describes all requirements for each of the component systems installed on a locomotive as set by a customer and each subsystem component might have been required to be designed individually. This design approach is still in use in some countries, and it works well in the case when only one major railway company operates its rollingstock fleet on the railway network across the whole country. However, this approach is not optimal when many rail operators with varying requirements are considered. In this case, it is better to use standardised locomotive products that can be built based on the modular component design approach where a series of locomotives designed for undertaking specific operational tasks can be assembled from the existing predesigned units. This approach offers benefits in terms of a high-quality product tested on many locomotive models and achieving an optimal price solution for each component that is selected to be used in a locomotive design [2].

Considering the complexity of the development of the detailed design specification, which would typically incur significant engineering costs, including the engagement of external consultants, there was a transition in the railway industry from the detailed specification to a performance specification. Based on the definition given in [1], the performance specification provides a list of tasks that includes how the locomotive should perform on the selected network, commonly with no reference on horsepower and tractive and dynamic braking effort requirements. In such cases, it is strictly up to the design engineer to deliver a locomotive configuration that meets the customer expectation, legislation and track access standards considering the routes where the locomotive is going to be operated. In this case, the application of train dynamics and locomotive multibody dynamics simulations is a great help to the designer. In such simulations, it is also necessary to consider requirements not only from the railway operators but also from railway network owners that want to know how much damage a new or modernised locomotive will introduce to their infrastructure [3-6]. The railway owners consider damage in terms of track damage (wear, rolling contact fatigue (RCF) etc.) for rails and track components caused by locomotives under various train operational and wheel/rail contact and adhesion characteristics [7].

Considering all the issues stated above, it is necessary that the performance specification should be extended and it should not only consider the railway operators' requirements, but it should also take into account the requirements set by the railway infrastructure owners in order to provide an optimal solution from the initial design to the actual locomotive operational stage. The extended performance specification would also contribute to increasing the knowledge and prediction possibilities of operational and maintenance requirements for the wheel-rail interface. To solve this task at the design stage and to avoid high costs and disruption of train operations on real railway networks during the testing and evaluation process, the assessment of all these design, behaviour and maintenance aspects for various locomotive operational scenarios should be performed through computer simulations.

In this paper, the methodology that can be used at the systems engineering design stage for computer analysis and simulations is described in Sect. 2. A literature review and locomotive studies, starting from developing a realistic locomotive design model, examples of key modelling components required for locomotive studies including developing a realistic locomotive design model, is provided in Sect. 3. The integration aspects of all engineering disciplines achieved by the incorporation of rail friction processes, the application of simplified and exact wheel-rail contact theories, and wheel-rail wear are detailed in Sect. 4. The usage of locomotive and train performance simulations including implementation with the co-simulation and parallel computing approaches on the High-Performance Computing (HPC) cluster is described in Sect. 5. Section 6 considers the modification of the locomotive design concept by the introduction of hybrid locomotive technologies into the existing $\mathrm{AC}$ and $\mathrm{DC}$ locomotive design solutions and their studies by advanced simulation approaches. Section 7 summarises the problems and limitations presented in locomotive traction studies in the way they are conducted at the present time and states the challenges that should be resolved in their future developments.

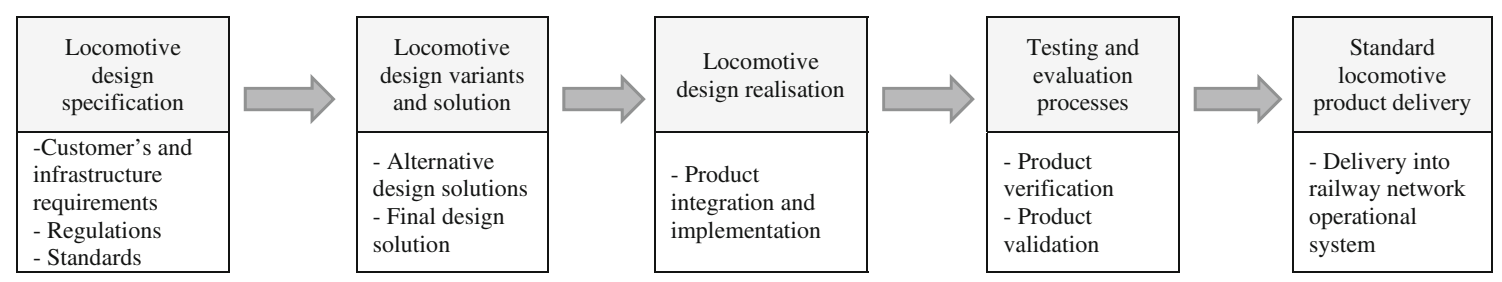

Fig. 1 Original design approach used for a standard locomotive product 


\section{Design methodology}

The proposed computer simulation methodology is based on a three-stage approach with the application of V-models. Some good reviews on how this is applicable in $\mathrm{V}$-models are published in $[8,9]$. However, the process should be reconsidered in terms of the application of digital twin technology and the specific requirements of a detailed and advanced locomotive modelling and design in combination with train studies. The latter should prove the concept of the development of a digital twin because, based on the definition provided in [10-12], the digital twin should include four important parts:

- a model of the object built based on an integrated multiphysics, multiscale, probabilistic simulation approach;

- an evolving set of data relating to the object;

- a means of dynamically updating or adjusting the model in accordance with the data;

- mirror and predict activities/performance over the life of its corresponding physical twin.

Considering these important parts and aspects of previous locomotive design studies published in [1,13] allows implementing the V-model approach for the advanced locomotive traction simulation and design studies based on several cycles with many stages of system integration activities involved during the development process as shown in Fig. 2.

Stage 1 represents the development of a multibody locomotive model. A fully established locomotive technique is described in [14], and the validation approaches are well described in [15-18].

Stage 2 represents the design of a mechatronic system of a locomotive that is based on the multidisciplinary engineering knowledge and the application of co-simulation techniques as described in [13, 19-21].

Stage 1 and Stage 2 generally consider the modelling of a locomotive as an individual rail vehicle, or they can also be used to perform as a model of a locomotive consist that can include two or four locomotives in one model. However, the latter approach might require quite significant computational resources.

Stage 3 is focused on the design of a whole locomotive/train/track system that includes a great number of models involving the complexities of track design and geometries, the non-linear wheel-rail contact interface characteristics and the numerical characterisation of wear processes considering tribological aspects and train operational scenarios. The latter includes not only a fullmechatronic model of the rail vehicles in the train but also a virtual train driver. Stage 3 should be realised on the virtual simulation platform that is commonly built on a High-Performance Computing (HPC) cluster. The digital twin model uses parallel computing and co-simulation technique between longitudinal train dynamics, vehicle dynamics and track dynamics (where a track model is implemented as a separate model) software packages [13, 22-25]. The process commonly uses one independent processor core on the HPC to simulate each vehicle (implemented in a multibody software package) in the train as it travels over the whole railway route. Individual cores then communicate with the longitudinal train dynamics simulation through the co-simulation interface to replicate actual train behaviour by means of the application of digital twin technologies. This requires significant computational resources (for example, a typical heavy haul train can consist of 3 locomotives and 240 wagons).

The implementation of such a simulation process provides the ability to conduct trade-off studies between potential locomotive design variations and ultimately define a design that should suit not only rollingstock owners but also railway owners. However, for the realisation of the proposed methodology, there are a great number of assumptions and tools that need to be made. This paper addresses these in the next sections.

\section{General concept for the development of a realistic locomotive multibody model}

This section discusses how to develop a reliable multibody locomotive model. Some background information regarding using multibody dynamics simulations for locomotive design is introduced first. Then an example of a locomotive model acceptance procedure is presented and discussed.

\subsection{Background}

The use of multibody simulations for verifying the performance of railway vehicles emerged at a commercial level in the 1980s, and has continued evolving to reliable and mature modelling techniques and software packages that are commonly used for efficient design, development and acceptance of modern railway vehicles [26]. In the case of running behaviour and vehicle dynamics approval tests for new or relocated locomotives, several standards worldwide allow substituting some of the field tests with multibody simulations (MBS) to reduce the cost, time and effort of physical tests [15, 27]. For instance, the Australian standard AS7509:2017 Rolling Stock Dynamic Behaviour [28], defines the dynamic behaviour requirements of railway vehicles, including locomotives, to reduce accelerated infrastructure degradation and reduce the risk of derailments. AS7509:2017 states that simulation tools can be 


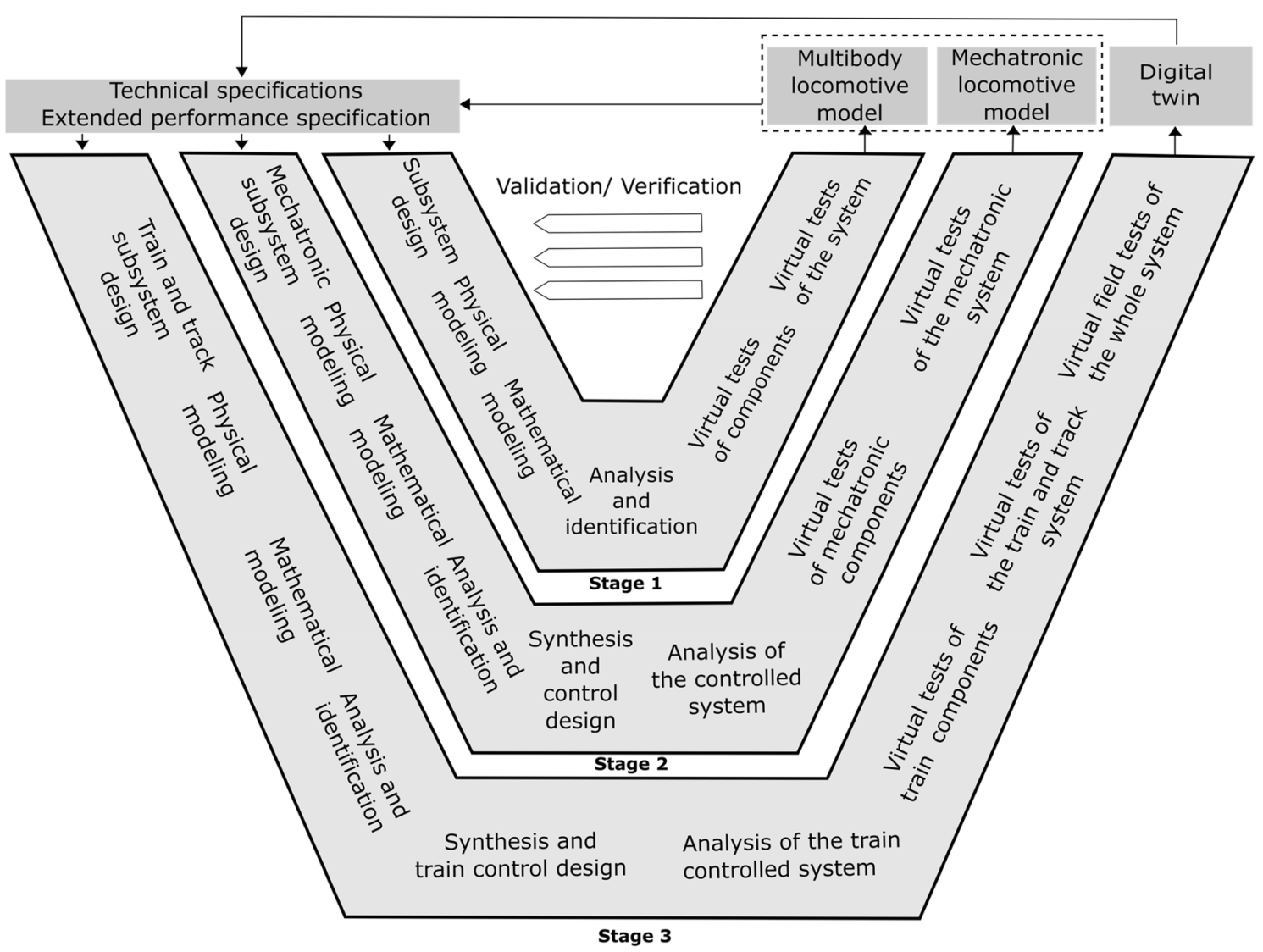

Fig. 2 Proposed V-model with several system integration stages for the design of a locomotive product

used as long as key elements of the vehicle simulation are validated through physical testing, and only industryrecognised simulation software can be used, referring, for example to the Manchester Benchmarks for Rail Vehicle Simulations [29]. Using railway simulations instead for field tests is especially useful when the test requires the vehicle to transit over specific isolated or cyclic track irregularities that could be hard or expensive to reproduce in the field. Similarly, the European standard EN 14363 [30] established the tests that a railway vehicle must pass for its running behaviour to be accepted for operation. The EN 14363 Annex T.3 [30] presents two methods for validating railway vehicle models for simulation of on-track tests in vehicle homologation context. Both methods involve comparison of measured versus simulated running dynamics quantities such forces between wheel and rail, car body lateral and vertical accelerations, bogie lateral acceleration, etc. All these standards [28, 30, 31] should be considered in locomotive studies because their final application of the standards can be summarised as written in [32]: "Complying with standards can be a substantial cost for suppliers of rolling stock and equipment, and for their customers. Providing evidence of compliance, as required by the Systems Engineering model, can be very time consuming. ... Guide books and reference volumes may well be useful documents, but there is no compulsion to follow their advice. A standard, however, states how things must be done. And generally, the supplier must prove that product is in accordance with the standard."

In addition to the use of locomotive and other railway vehicles multibody simulations (MBS) for "virtual homologations", there are emerging applications where researchers use more complex models that include the locomotive traction system, enabling, for example predictions of wheel-rail wear and RCF [33].

In the process of formulating a locomotive dynamic model to be used in traction studies, several disciplines including electrical engineering, mechanical engineering and civil engineering are involved. In general, there are four common modelling approaches [13]: implementing a locomotive model using a general-purpose scientific commercial software like MATLAB/Simulink [34-36]; implementing a locomotive model using in-house software [37]; implementing the locomotive model in commercial multibody software packages [13, 38, 39]; or co-simulation approaches where the multibody locomotive model and the traction mechatronic system are modelled independently in two different software packages that interchange data 
during the simulations [19-22]. The latter approach allows for advanced traction and track damage studies as it allows for advanced traction models and locomotive models to be independently configured with solvers that can adapt better to the individual subsystems [21]. In this way, it is more viable to account for the wheel-rail creepages produced by acceleration and electrodynamic braking events [40]. As dynamic braking (DB) and acceleration are controlled by the traction locomotive components that form a complex mechatronic system, there have been recent co-simulation approaches to model the vehicle multibody dynamics using one solver whilst calculating the locomotive traction subsystem behaviour in parallel using an independent solver. In addition to rail damage, co-simulation of different locomotive subsystems opens new research possibilities, for instance studying innovative condition monitoring approaches to detect faults that affect several locomotive subsystems. A good example is detecting wheel polygonisation or wheel flats from the electrical signals in the locomotive traction system [41]. Additionally, it allows setting up simulations that consider not only the effects of a single locomotive, but also the influence of full train consists with several locomotives and wagons [22].

\subsection{Locomotive model acceptance procedure}

As more railway regulatory organisations continue to acknowledge the use of MBS for virtual homologations and the development of complex co-simulation studies, researchers at the Centre for Railway Engineering have proposed the Locomotive Model Acceptance Procedure (LMAP) to incorporate best practices as used in Australia in the development of locomotive MBS [15]. This section exemplifies a locomotive model acceptance procedure using an AC locomotive as an example. The locomotive is modelled as a 134-t vehicle with a Co-Co wheel arrangement, in which the car body is coupled to two bogies, each one with three independent wheelsets driven by one traction motor each. The LMAP comprises three stages that cover the locomotive model creation and debugging, dynamic tests included in railway standards, and complementary tests related to the traction system. Each stage in turn requires tests with specific procedures and acceptance criteria. The process summarised in this section is based on [13] and [15], exemplified with a recent project developed at the Centre for Railway Engineering. Figure 3 summarises the proposed LMAP.

\subsection{Development of a locomotive model}

The locomotive multibody model is usually built with lumped masses that interact through stiffness and damping coupling elements. Depending on the approach, the masses of bodies like traction motors are distributed into the

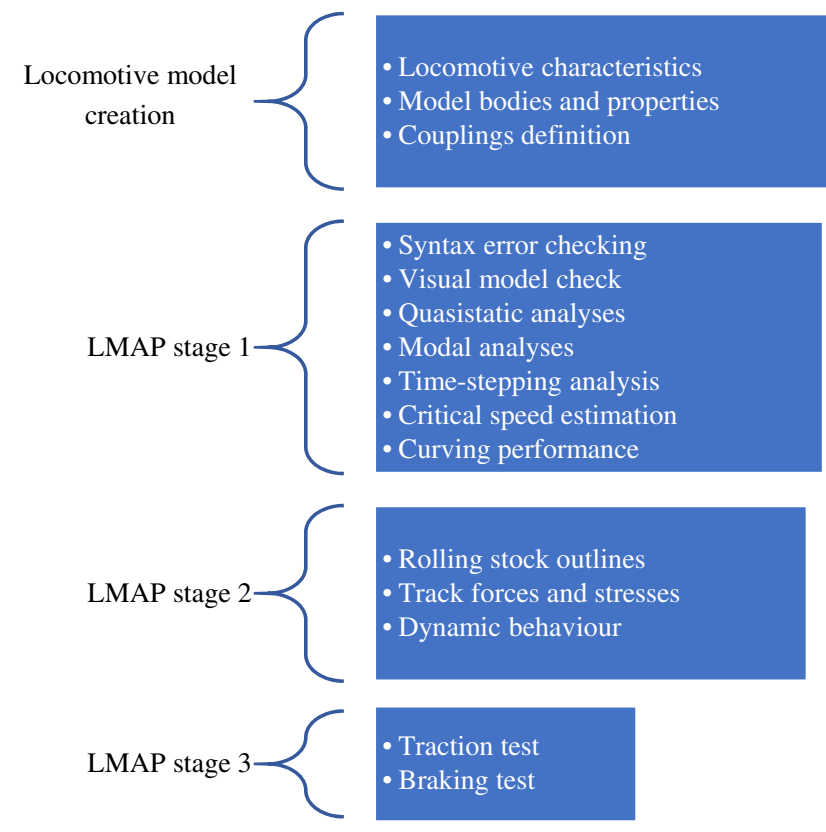

Fig. 3 Locomotive model acceptance procedure

nearby bodies to facilitate the model creation. Since it is in general difficult to get all data needed to build a good simulation model, the model developer should pay special attention in defining the input parameters for the creation of the models [42]. A good starting point is the locomotive datasheet, were information about the maximum operating speed, vehicle mass, vehicle wheelbase, distance between wheelsets and other general dimensions can be found. In this way, a general diagram that presents the bodies and the distances within them can be defined as shown in Fig. 4. When the locomotive equipment, including for example the engine, generator, fuel tank, compressor and other equipment masses and locations in the vehicle are available, it is possible to create a locomotive body representation using $\mathrm{CAD}$, accounting for the equipment masses and distribution to facilitate the estimation of the car body centre of mass and rotational inertias. Similarly, using the drawings of the bogie frame, wheelsets, and bolster, it is possible to trace components general shape to obtain a three-dimensional representation that allows a better estimation of the centres of mass and rotational inertias.

Following the definition of the bodies that will form the multibody model, the rotational inertias, centres of mass and general dimensions and their degrees of freedom, the locomotive bodies and their properties are then set up in the multibody software environment. Subsequently, the primary and secondary suspension components and their characteristics are identified. Most of the MBS commercial software packages have various methods for factoring the stiffness, damping and friction nonlinearities that govern the behaviour of the suspension components, including 

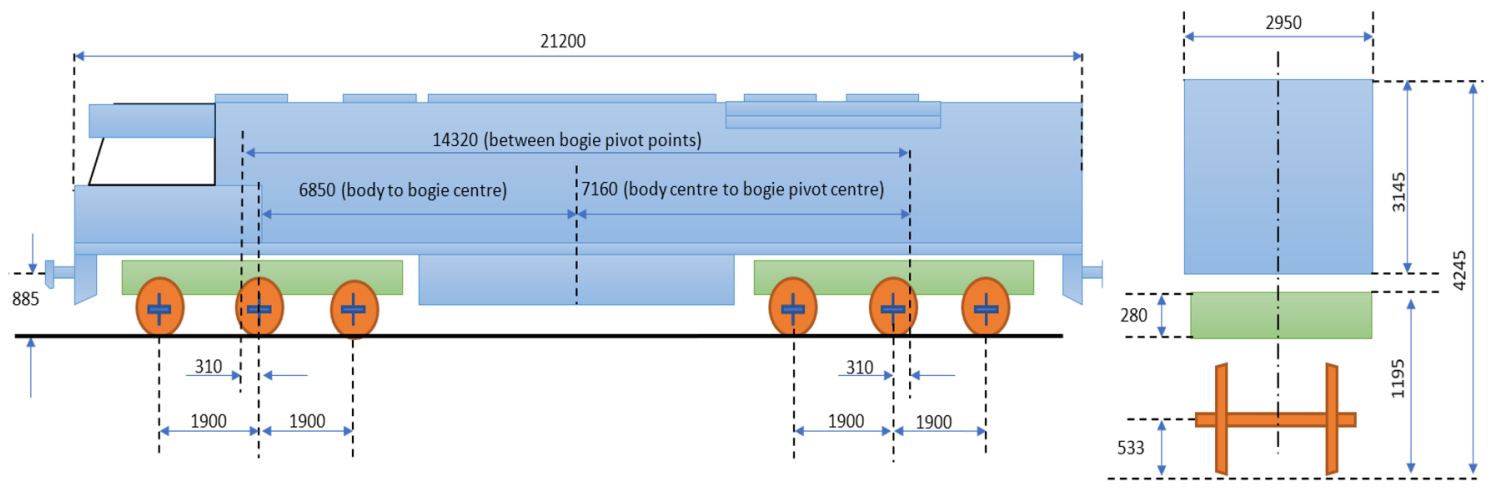

Fig. 4 Locomotive bodies and general dimensions diagram (unit: mm)

general models for coil springs, buffers, airbags, friction blocks, bump stops etc. For instance, when using GENSYS MBS software [42] the nonlinear behaviour of a stiffness coupling between two bodies can be formulated through a piecewise function of displacement versus forces. Figure 5 shows a general view of the AC locomotive model implemented in GENSYS. Figure 6 presents a zoom in on the AC locomotive semi-steering bogie model highlighting the primary and secondary suspension components. The wheel-rail profiles that will be used in the subsequent test are also defined at this moment of the model development based on the requirements provided in AS7509:2017 Rolling Stock Dynamic Behaviour [28].

\subsection{LMAP stage 1}

The LMAP Stage 1 process aims at guaranteeing the model was correctly formulated inside the multibody software environment and that it generates stable and reasonable results for static and dynamic scenarios with a specific solver and time step. This stage includes syntax error verification, visual model checks and quasistatic analyses to ensure the locomotive bodies and suspension components are deformed or displaced as expected. Figure 7 shows the graphic results of the vertical and lateral quasistatic analyses. For the vertical test, the car body is displaced $50 \mathrm{~mm}$ downwards, as shown in Fig. 7 left. The vertical displacement test is considered passed if the wheel-rail vertical forces increase in correct proportion to the total stiffness of the primary and secondary suspension systems. Similarly, for the lateral test, the car body is displaced $50 \mathrm{~mm}$ laterally. This test is considered passed if the bogie frame roll angle corresponds to the car body displacement direction.

For the modal test, the eigen frequencies and relative damping values are calculated for each mode found in the vehicle model [42]. The locomotive model passes the test

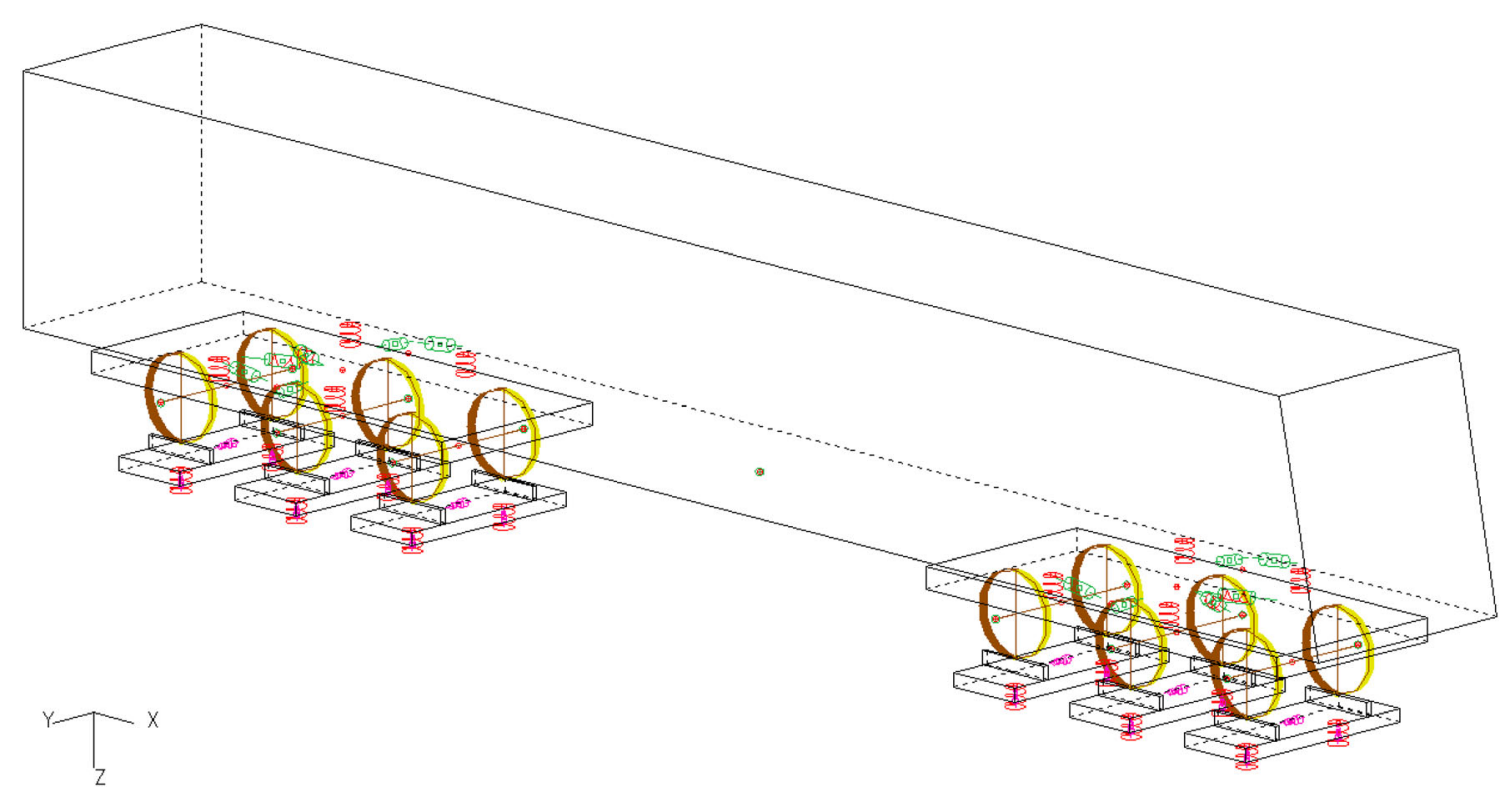

Fig. 5 AC locomotive multibody model in GENSYS 
Secondary suspension system elements (per bogie):

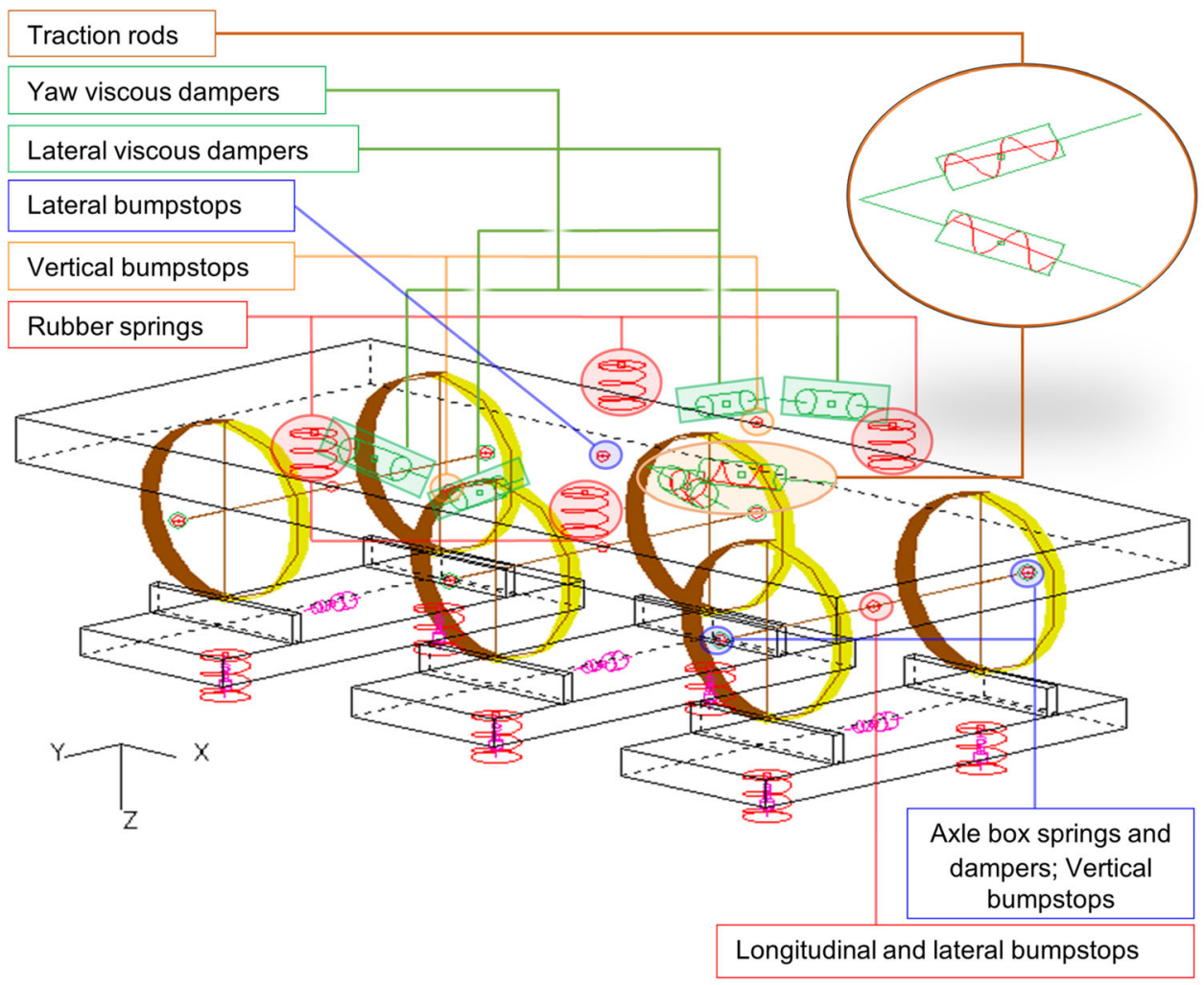

Primary suspension system elements (per wheelset)

Fig. 6 Zoom in on semi-steering bogie multibody model implemented in AC locomotive model showing primary and secondary suspension components
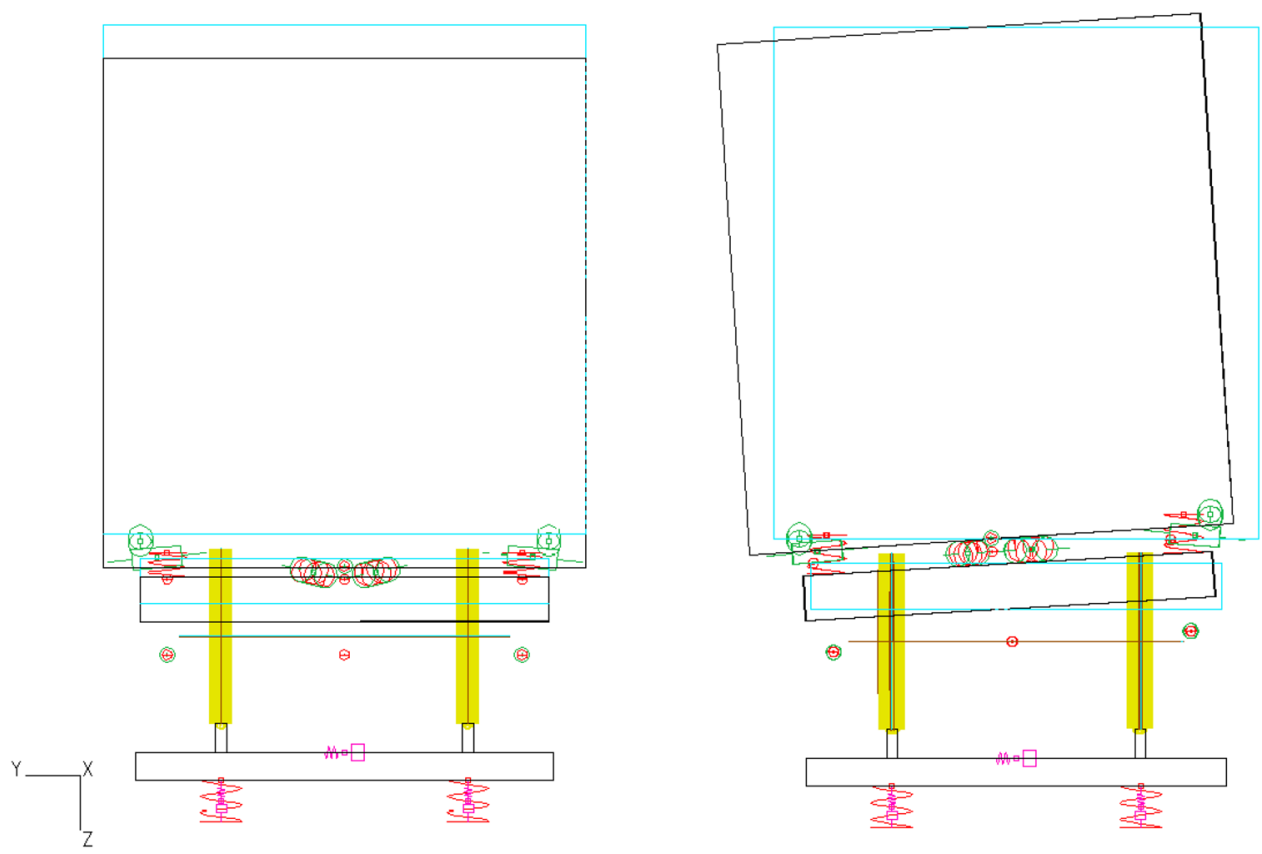

Fig. 7 LMAP stage 1 quasistatic analysis example. Left: car body displaced $5 \mathrm{~cm}$ towards the track; Right: car body displaced laterally $5 \mathrm{~cm}$ 
when there are no negative damping values or high eigenvalues exceeding $5000 \mathrm{rad} / \mathrm{s}$. Subsequently, for the time-stepping test, the locomotive model is run on an ideal tangent track at various speeds with fine and coarse time steps. The model passes the test when there are no unexpected displacements or rotations of bodies. The critical speed estimation test is conducted by running the locomotive model at a high speed on an ideal tangent track with a lateral track irregularity that triggers vehicle hunting motion. The vehicle speed is diminished at a constant rate until it stabilises. The hunting behaviour should disappear above $110 \%$ of the proposed operational speed for the model (rolling stock and track conditions for the model are defined in AS7509 [28]) to pass the test. Figure 8 shows an example of the critical speed estimation results for an $\mathrm{AC}$ locomotive. The simulation started at $300 \mathrm{~km} / \mathrm{h}$ and diminished at a constant rate of $-5 \mathrm{~km} / \mathrm{h}$ per second. The top plot shows the lateral displacement of wheelsets while the bottom plot presents the vehicle speed. It is seen that, for this vehicle, the lateral movement of the wheelsets stabilised after $24.5 \mathrm{~s}$ corresponding to $175 \mathrm{~km} / \mathrm{h}$.

One of the possible mechanisms for validating the dynamics produced by the model is comparing the locomotive model wheelsets' angle of attack (AoA) when negotiating a curve with AoA of field measurements. The wheelset AoA should have reasonable agreement for low and high-speed cases. The AoA comparison is considered as one of the field measurement validations required by dynamic behaviour standards such as AS7509 [28]. Figure 9 shows the AoA results of the wheelsets of a single three-axle bogie for simulated versus measured indicative data.

Other approaches for validation of simulation models by comparison with on-track tests can be found in [16, 17].

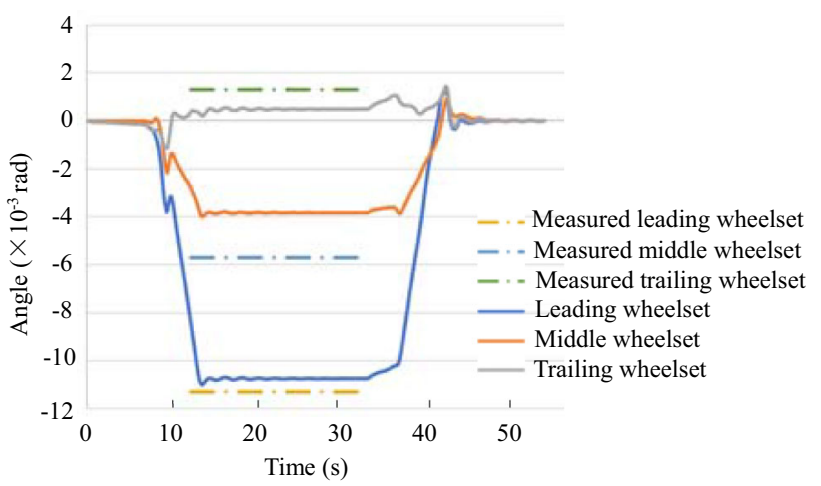

Fig. 9 Angle of attack comparison for AC locomotive model versus field indicative measurements

\subsection{LMAP stage 2}

During this stage, the dynamic behaviour produced by the locomotive model is evaluated against the dynamics required by a particular standard. In the case of the Australian Standard AS7509 [28], for example, the verification includes hunting, twist, curve negotiation, isolated and cyclic track defects negotiation among others. For each test, the standard mentions the acceptance criteria in terms of wheel unloading, $\mathrm{L} / \mathrm{V}$ forces ratio and car body vertical and lateral acceleration limits, as well as how the output signals should be postprocessed. Most of the tests of this stage are performed at the maximum locomotive design speed, with wheel and rail profiles in worn conditions and typical track irregularities superimposed over the test track features. The discrete track defect tests include flat humps that represent bridges or level crossings faults and curved dips that correspond to track subsidence caused by poor drainage. Cyclic track defect tests, on the other hand, are

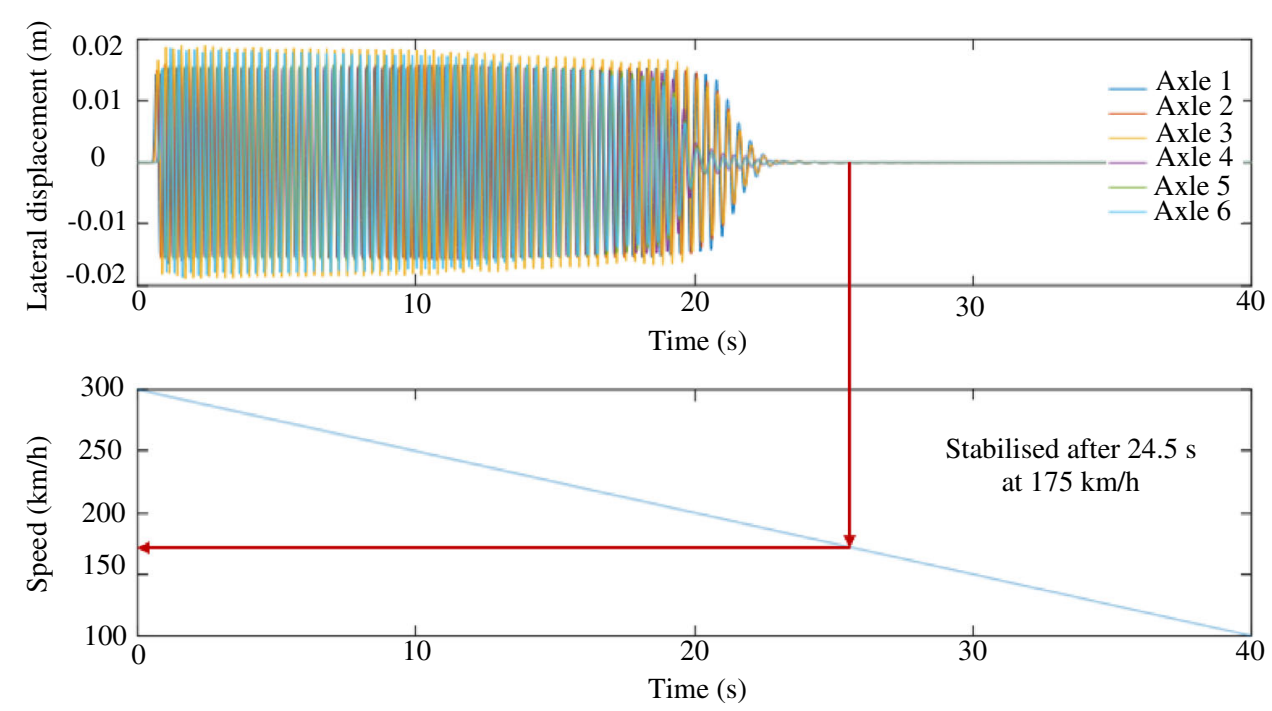

Fig. 8 Example of critical speed estimation results for an AC locomotive model 
set at distances that trigger car body pitch, bounce and harmonic roll. Figure 10 shows the example results of the harmonic roll test for an AC locomotive. The lateral and vertical acceleration was obtained for the car body on top of the bogie centres. The acceleration signals were lowpass filtered with a fourth-order Butterworth filter with a cut-out frequency at $10 \mathrm{~Hz}$.

\subsection{LMAP stage 3}

The final stage involves the development and testing of the locomotive traction control system that represents the $\mathrm{V}$-model Stage 2 shown in Fig. 2. The traction system for a diesel-electric locomotive includes a diesel engine, an AC or DC alternator, traction motors and an inverter in the case of using an AC traction motor. The system produces traction or braking forces, and it is controlled through throttle notch positions. The complete traction system mechatronic model should capture the main energy transformation processes that occur at each stage, including power delivery delays and energy losses. In the diesel engine output, for example, there are delays in response to throttle changes as a function of engine temperature, emission control requirements and other variables affecting the system power capabilities. Figure 11 shows an alternator voltage regulator, which is part of a diesel-generator plant, used for the modelling of an AC locomotive traction system.
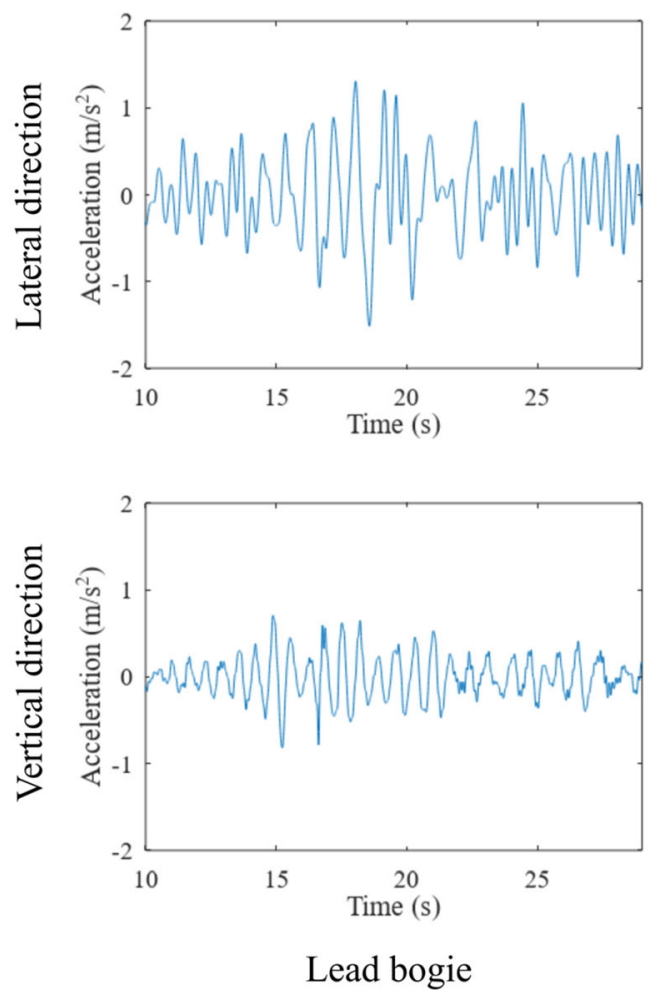

Fig. 10 Example of harmonic roll test car body acceleration results
Figure 12 shows the mechatronic approach used for modelling of a whole locomotive system in Gensys and MATLAB/Simulink software products [23].

Both acceleration and DB are tested for the whole range of notch positions. The equivalent drawbar force is input to the locomotive model through a sky-hook element attached to the vehicle car body to generate load to the vehicle traction system. The main testing categories involved in the LMAP stage 3 involve a variety of acceleration and braking scenarios [13], for example gradient starting, allweather adhesion limits, stopping distances, gradient parking, among other tests. Figure 13 shows the results of traction effort (TE) and DB tests for the full spectrum of notch positions, allowing the correct verification of the traction mechatronic system model across the whole locomotive speed range.

\section{Key engineering operational aspects with uncertainties in the system modelling and prediction approaches}

This section first discusses wheel-rail friction that has high uncertainty. A number of advances in wheel-rail contact modelling and wheel-rail wear simulations with the specific consideration of locomotive traction are then presented.
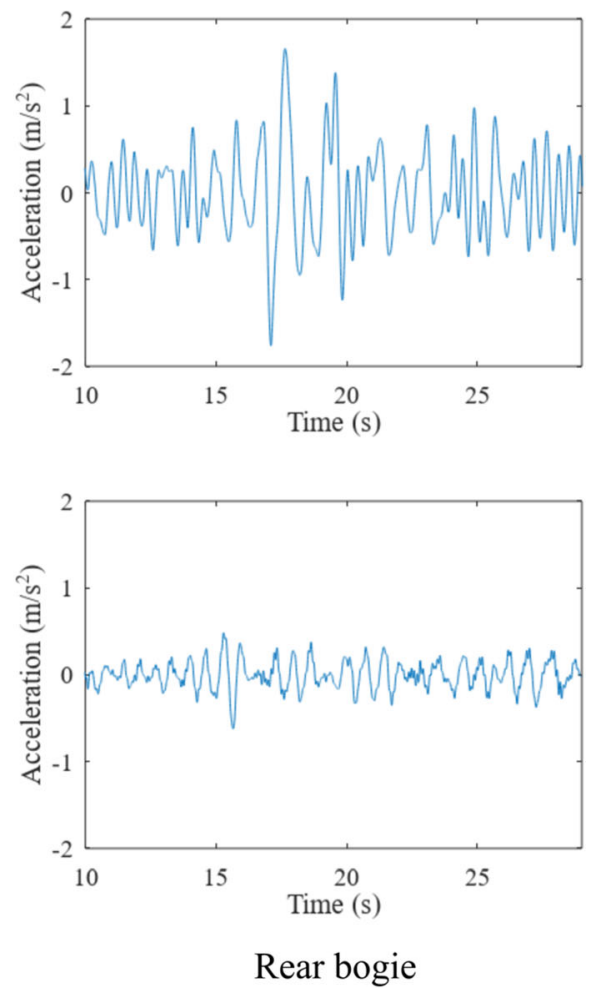

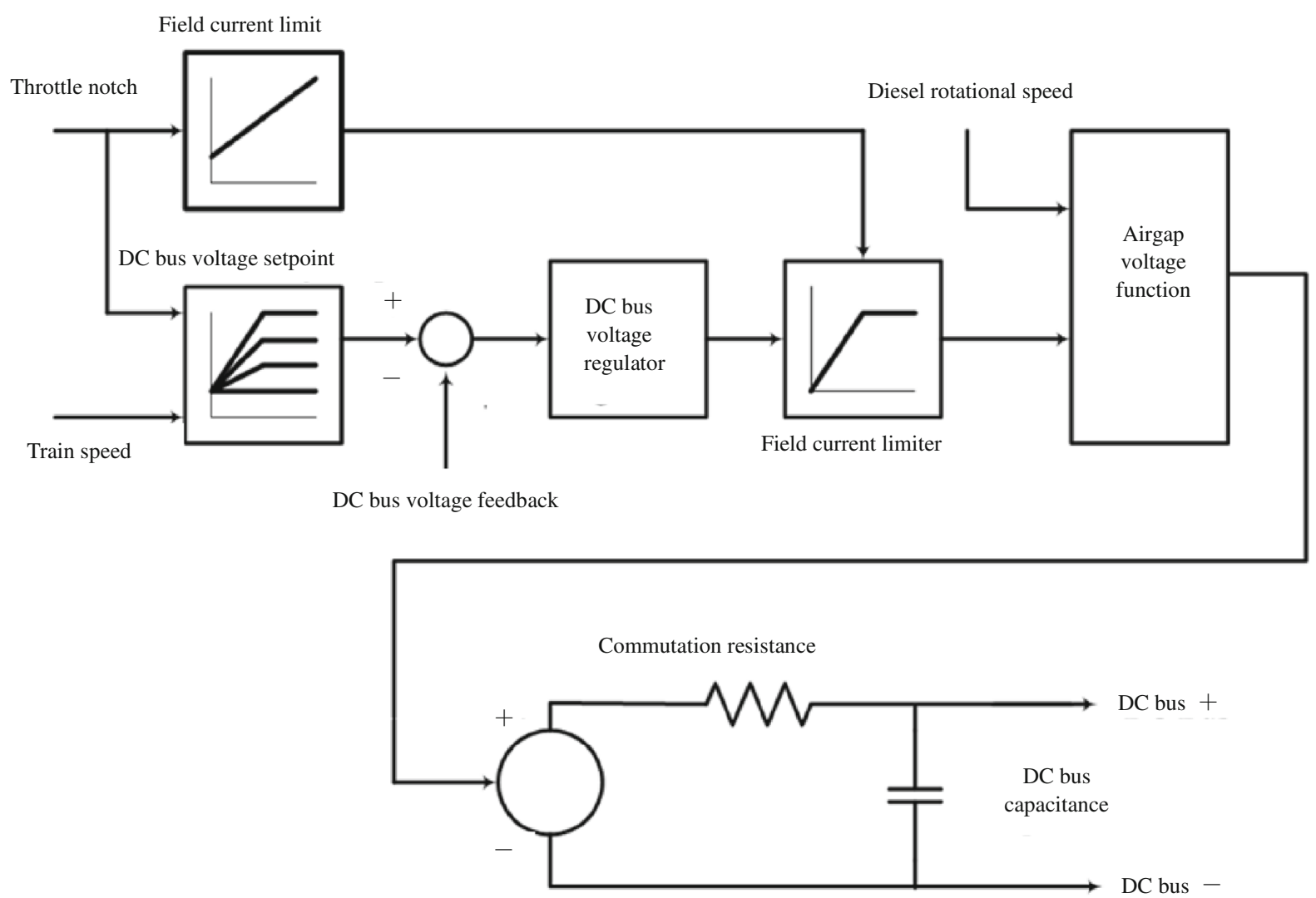

Internal alternator voltage

Fig. 11 Alternator voltage regulator in a locomotive traction system model

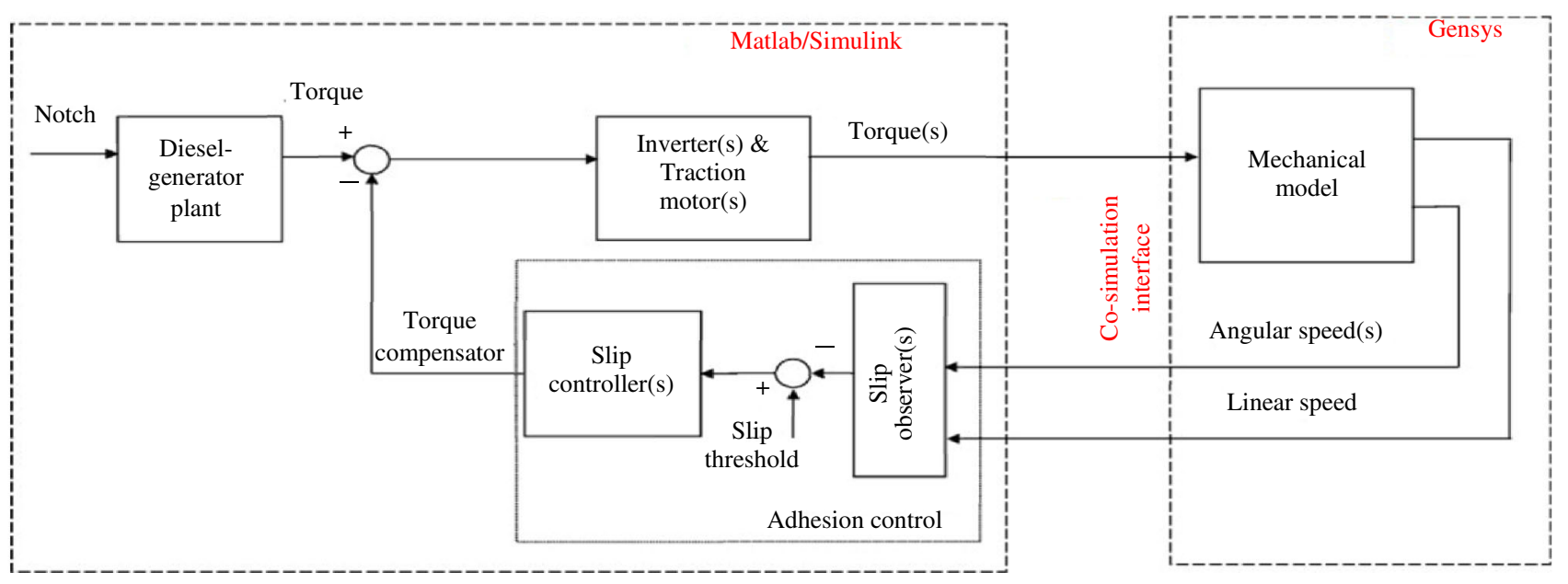

Fig. 12 Co-simulation of a whole locomotive system in Gensys and Matlab/Simulink software products

\subsection{Friction at the wheel-rail interface}

Discussions about wheel-rail friction include the significance of wheel-rail friction, friction characterisation and friction models.

\subsubsection{Friction in locomotive traction studies-Why is friction important for locomotive traction studies?}

It is essential to understand traction and its limiting factors before conducting locomotive traction studies. The traction 

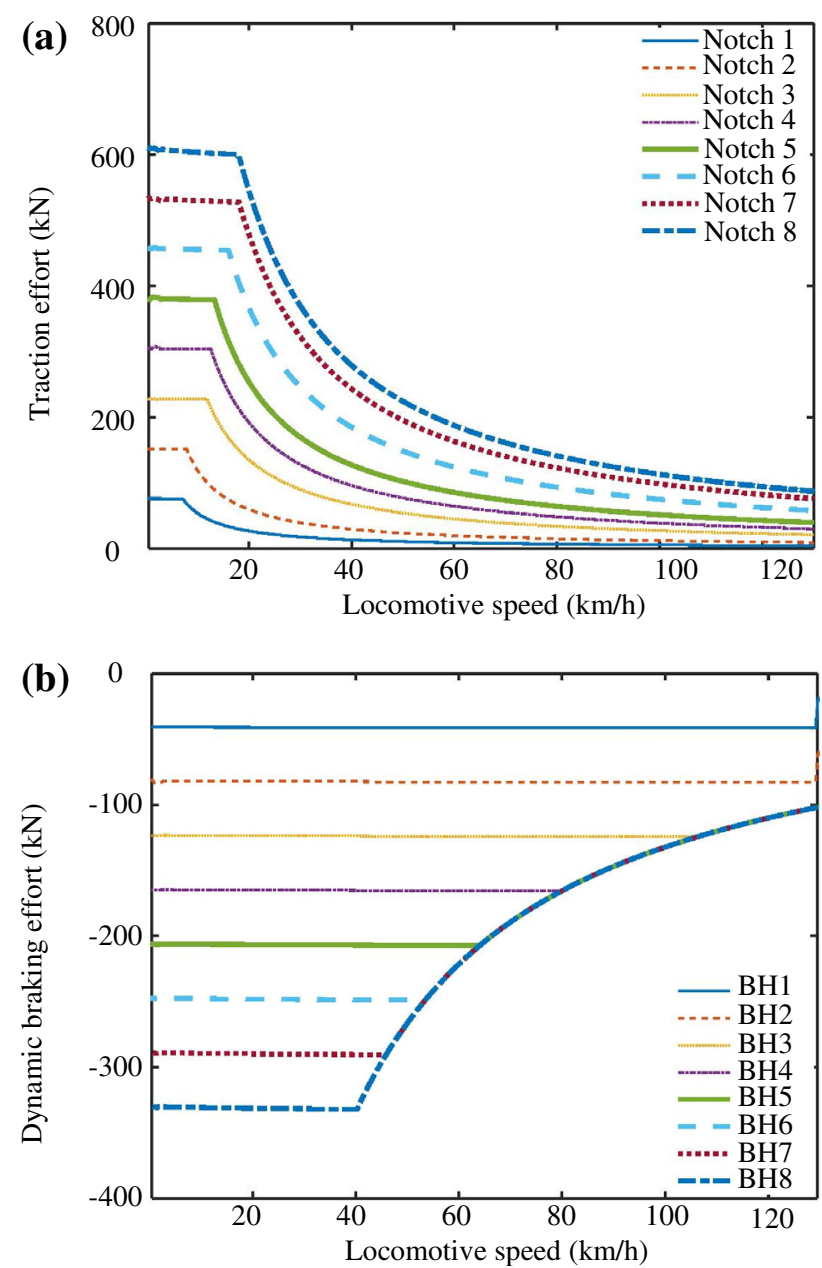

Fig. 13 a Traction effort versus locomotive speed characteristics for each notch position and $\mathbf{b}$ dynamic braking effort versus locomotive speed characteristics for each BH (brake handle) position

is the utilised adhesion through traction control. This means traction is always limited by the available adhesion between wheels and rails. Furthermore, the adhesion available between wheels and rails is limited by the dynamic friction coefficient which varies as the slip changes. Also, dynamic friction is limited by static friction. Overall, the traction is dependent not only on adhesion but also on the friction between wheels and rails.

As explained above, the friction-slip curves are influenced by the adhesion processes between the wheels and rails. The adhesion processes are substantially related to the friction processes that are characterised by the surface conditions of the contact between wheels and rails [43-46]. Since the wheel-rail interface is an open system, the friction process is affected by many operational and environmental parameters which ultimately affect the traction control. This is the reason why traction control of the locomotive requires a proper definition of the adhesionslip/(creep) characteristics curve as shown in Fig. 14 [47].

\subsubsection{Friction characterisation-How is friction characterised in locomotive traction studies?}

There are five potential approaches to experimentally characterise the friction condition between wheel-rail contact [48]:

- Small-scale laboratory test

These tests are conducted to gain a fundamental understanding of friction. The advantages of such an approach are control over test parameters, ease to prepare the test specimen, easy data acquisition, and low cost. The specimens used in these tests are extracted/cut from the larger bodies. Thus, scaling of the contact condition is essential to represent the realworld condition. The main approaches used in this test are pin-on-disc [49, 50], twin-disc [51, 52], or scaled roller rig [53, 54].

- Full-scale laboratory test

To exactly represent the wheel-rail contact condition and reduce the uncertainty due to the scaling problem, fullscale test rigs are also in use to characterise the friction condition. The available full-scale test rig can be classified into three categories [55]: locomotive test rig, bogie test rig, and wheelset test rig. With the locomotive test rig, more parameters can be evaluated with higher accuracy which decreases respectively with bogie and wheelset rigs. However, the higher accuracy needs a trade-off with the higher cost of operation and maintenance.

- Field test utilising special instrumented vehicle

Instrumented bogies and instrumented wheelsets are used to quantify the friction at wheel-rail contacts [56, 57]. Since the testing is performed under real-world scenarios, the results are reliable. However, it is one of the costlier approaches, a possible variation of parameters during the test (e.g. variation of lateral creepage) is limited and control over the test parameters may be challenging.

- Field instruments capable of measuring the traction-slip relationship

Different types of tribometers are used to measure the traction-slip characteristics. Some of them are attached to the road-rail vehicle (also called hi-rail vehicle) and some are hand-operated [58, 59].

- Locomotive field tests

The measurement of locomotive traction coefficient versus slip curves [60-63] can be used as indicator of friction conditions at the wheel-rail interface.

\subsubsection{Friction models-How is friction characterised in the numerical model?}

Many researchers have developed mathematical models to describe the friction characteristics of the wheel-rail 


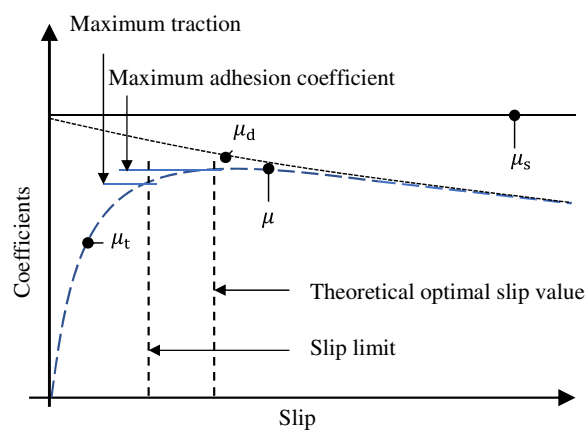

\begin{tabular}{cl}
\hline Symbol & \multicolumn{1}{c}{ Explanation } \\
\hline$\mu_{\mathrm{s}}$ & $\begin{array}{l}\text { Maximum static friction coefficient. } \\
\mu_{\mathrm{d}}\end{array}$ \\
& $\begin{array}{l}\text { Maximum dynamic friction coefficient. It is } \\
\text { less than or equal to } \mu_{\mathrm{s}} .\end{array}$ \\
$\mu$ & $\begin{array}{l}\text { Adhesion coefficient. Also identified as } \\
\text { available adhesion level. It is limited by } \\
\text { dynamic friction. The maximum adhesion } \\
\text { coefficient is less than or equal to } \mu_{\mathrm{d}} \text {. }\end{array}$ \\
& $\begin{array}{l}\text { Traction coefficient. It is defined as the utilised } \\
\text { adhesion under traction control. In general, it is } \\
\text { synonymously used as an adhesion coefficient. } \\
\text { However, it is limited by the tractive effort } \\
\text { applied and is always less than or equal to the } \\
\text { adhesion coefficient. }\end{array}$ \\
\hline
\end{tabular}

Fig. 14 Relation of friction coefficient, adhesion coefficient, and traction coefficient

contact. A comprehensive review of the application of friction models in wheel-rail adhesion calculation has been conducted by Yuan et al. [63]. The friction models can be categorised into three types, namely:

\section{- Coulomb model}

According to the Coulomb model, the wheel-rail adhesion coefficient remains constant after reaching its saturation value $[64,65]$. However, it is observed that the adhesion coefficient varies with the slip [66] (i.e., falling friction phenomenon).

$\mu=c * \operatorname{sgn}(v)$,

where $\mu$ is the friction coefficient, $c$ is a constant, sgn is the sign function, and $v$ is the sliding speed.

\section{- Rational model}

In this model, the falling friction phenomenon is included. The effect of the sliding speed is included, and the curve is more consistent with the fact that the friction coefficient decreases with the increase in the sliding speed.

Table 1 Rational models to calculate wheel-rail adhesion

\begin{tabular}{lll}
\hline S.N. & Friction models & References \\
\hline 1 & $\mu=\frac{\mu_{\mathrm{s}}}{1+0.23 v}$ & {$[67]$} \\
2 & $\mu=\frac{\mu_{\mathrm{s}}(f, W, V)}{1+\alpha(f, W, V) v}$ & {$[68]$} \\
3 & $\mu=0.15+\frac{0.45}{3+v}$ & \\
4 & $\mu=\frac{0.03}{0.2+v}+\frac{15}{100+v^{2}}$ & \\
5 & $\mu=\frac{0.3}{2+v}+\frac{15}{100+v^{2}}$ &
\end{tabular}

In S.N. $1, \mu_{\mathrm{s}}=0.3$ and in S.N. $2, \mu_{\mathrm{s}}(f, W, V)$ and $\alpha(f, W, V)$ are the fitting parameters dependent on the friction condition $(f)$ at the wheelrail contact, axle load $(W)$ and speed $(V)$ of a rail vehicle [68]
Also, the friction curve is more flexible than the Coulomb model. Friction models based on the rational method are presented in Table 1 . The unit of $v$ in formulas is $\mathrm{m} / \mathrm{s}$.

- Exponential model

An exponential model can be represented by

$\mu=a \mathrm{e}^{-b v}+c$,

where $\mu$ is the friction coefficient, $a, b$ and $c$ are the undetermined parameters, and $v$ is the sliding velocity. The characteristic of an equation containing an exponential term is that the resultant of the equation initially decreases rapidly when the exponential term is negative. The rapid initial declination gradually approaches zero with the rise in the independent variable. Such characteristics replicate the falling friction phenomenon. Thus, the exponential friction model has been broadly used to evaluate wheel-rail adhesion. Friction models based on the exponential method are presented in Table 2 .

Table 2 Exponential models to calculate wheel-rail adhesion

\begin{tabular}{lll}
\hline S.N. & Friction models & References \\
\hline 1 & $\mu=\mu_{\mathrm{s}}\left((1-A) \mathrm{e}^{-B v}+A\right)$ & {$[71,72]$} \\
2 & $\mu=0.175+0.175 \mathrm{e}^{-1.5 v}$ & {$[73]$} \\
3 & $\mu=0.32+0.18 \mathrm{e}^{-6 v}$ & {$[74]$} \\
4 & $\mu=0.15+0.15 \mathrm{e}^{-\log _{\frac{2 v}{3}}}$ & {$[69]$} \\
5 & $\mu=0.33+0.18 \mathrm{e}^{-\log ^{\frac{2}{1.25}}}$ & {$[66]$} \\
\hline
\end{tabular}

In S.N. $1 \mu_{\mathrm{s}}$ is the maximum coefficient of friction, $A$ is the ratio of the limit friction coefficient at infinity slip velocity to the maximum friction coefficient, $v$ is the sliding velocity (also called the magnitude of the slip/creep velocity vector) and $B$ represents the coefficient of exponential friction decrease, $\mathrm{s} / \mathrm{m}$ 


\subsection{Advances in contact models for traction studies}

The study of the interaction between wheel and rail is essential to explain locomotive traction studies. Such interaction is numerically explained through the wheel-rail contact model. Therefore, current locomotive traction studies have been widely focused on the development of wheel-rail contact models to use in specialised rail vehicle multibody software products. This contact model used for traction studies is the most computationally expensive part/module in railway multibody simulations. The development of an accurate and fast wheel-rail contact model is a complex and still ongoing area of railway research.

The major parts of the wheel-rail contact model are the geometrical contact module, the normal contact module, and the tangential contact module. The geometrical module deals with wheel-rail profiles and detects the location and size of the contact patches. This module requires the most computational effort (around 70\%) among all the modules. The normal contact module determines the shape and dimension of contact patches and defines the normal pressure distribution on the contact patch. Finally, the tangential contact module analyses the relationship between creepage and creep forces on the contact area. These three modules interacting simultaneously produce an accurate result. In general, the most accurate methods require interaction between all three modules which requires higher computational time. On the other hand, simplified methods neglect the interaction between these modules, thus needing less computational time but leading to less exact results. For traction studies, the contact model can be classified into three categories according to the computational complexity as shown in Table 3.

In the simplified contact model, the geometrical module and the normal module are ignored and a constant value for the contact patch is used. To solve the tangent task, the Polach model is implemented. The exclusion of the most computationally demanding geometrical module makes this approach relatively fast. Since the change in wheel-rail geometry is not included in the simplified model, such an approach cannot be considered accurate. To overcome some of the limitations of the simplified approach, the geometrical module is separated into online and offline segments in a hybrid approach. Those sections in a hybrid algorithm that have less influence on dynamic operation are assigned as the offline part [87] where the contact parameters are precomputed and stored in a look-up table. The parameters are retrieved by interpolation during the dynamic simulation. Therefore, a compound contact approach includes a hybrid method to solve the geometrical problem, Hertzian contact to solve the normal task in combination with the Polach theory or the Modified Fastsim to solve the tangent task. The compound approach holds better trade-offs between the computational speed and accuracy of the result, and this approach is widely accepted in traction studies. In the complex contact approach, the geometrical module uses online contact search algorithms to determine contact parameters using an iterative procedure during the dynamic simulation. Consequently, this approach requires huge computational time to solve the geometrical module. Many promising nonHertzian algorithms [77-80, 88] are being implemented which are gradually improving the computational speed as well as the accuracy, but further advancements in the algorithm and/or computational approach (e.g., parallel computing) are essential.

The Polach [60], Fastsim [76], lookup tables [83] and FaStrip [82] approaches are recommended for the V-model Stage 1 when considering traction studies (see Fig. 2). The Polach [60] and modified Fastsim [72] should be used for the V-model stage 2 (see Fig. 2) modelling exercises. The modified Fastsim can be used for locomotive/track damage studies in the V-model Stage 3 (see Fig. 2), but if the computational capabilities are available, then "the best option for performing wheel or track damage studies is to use the Exact theory developed by Kalker directly in the simulation procedure to solve the contact mechanics task at the wheel-rail interface" [88].

\subsection{Wheel-rail wear in traction studies}

In general, wear is a process in which the surface layers of solid bodies are ruptured because of the mechanical action against each other [43]. In wheel-rail wear, the bodies in

Table 3 Classification of contact model according to the computational complexity to study traction

\begin{tabular}{lllc}
\hline Computational complexity & Geometrical module & Normal module & Tangent module \\
\hline Simplified & Constant & Constant & Polach [60] \\
Compound & Hybrid & Hertz [75] & Polach [60], Fastsim [76], Modified Fastsim [72] \\
Complex & Hertz [75], non-Hertzian [77-81] & Polach [60], Fastsim [76], Modified Fastsim [72], \\
& & & FaStrip [82], USETAB [83], Extended Contact \\
& & [81, 84-86] \\
\hline
\end{tabular}


action are wheel and rail and the mechanical action appears in the form of frictional force. The quantitative definition of wheel-rail wear is the displacement of material from the wheel-rail contact surface. The wear is an unavoidable phenomenon when a train is in motion. This means the amount of wear should also be assessed in locomotive traction studies.

One of the major impacts that need to be considered due to wear in the traction studies is the change of the shape of the contacting surfaces. The change in the wheel-rail profile redistributes the contact areas on wheel and rail. However, the amount of wear is negligible in each iteration and modifying the shape of the wheel-rail profiles in every iteration involves a high computational effort. Thus, after a fixed number of iterations, the contact patch shape evolution due to the accumulated wear (i.e., wear depth) is determined and the contact surface is modified.

Many researchers around the world are working on wheel-rail wear. As a result, many wheel-rail wear models are available, including the models developed by KTH Royal Institute of Technology [89, 90], the University of Sheffield [91-93], British Rail Research [94, 95], the University of Florence [96-98], the Technical University of Budapest [99], and the University of Coimbra [100]. The wheel-rail wear is dominantly dependent on the friction at the wheel-rail interface. Since the interface is an open system, the friction condition is influenced by many external factors. One of the factors is a third-body interfacial layer at the wheel-rail contact interface (e.g., ironoxide wear debris, oil spill, leaves, friction modifiers). However, most of the wear models are developed based on the limited frictional condition variation as shown in Table 4 . The wear models may not be suitable to implement under different friction conditions that is not considered during development and validation. Another factor is the material used for the wheel and rail. Most of the wear models are developed for specific wheel-rail material combinations and using such models for different materials may not be applicable because of the change in wear rate. Although a wear model for each scenario would be ideal, it will be practically challenging to completely incorporate them into multibody simulations. Therefore, correction factors have been used to adjust the existing wear model according to the new scenarios [101].

\section{Parallel computing in locomotive traction studies}

Locomotive traction studies have now been developed to an advanced level where detailed and complex models are often used, especially for the development of digital twins (see V-model Stage 3 in Fig. 2). These models require higher computational efficiency that can be facilitated by using parallel computing techniques [24]. This section first introduces some basics regarding parallel computing. Then two simulation cases that have used parallel computing and can be used for locomotive traction studies are presented.

\subsection{Parallel computing basics}

The simplified concepts of parallel computing and serial computing are shown in Fig. 15. The essence of parallel computing is to use multiple computing units or computer cores to process multiple computing tasks concurrently. The primary benefit of parallel computing is faster computing speed. For a computing problem to be solved using parallel computing, the problem should be able to be partitioned into a number of independent computing tasks. The independence is often temporary, which means for certain steps of each calculation cycle, these computing tasks do not need information exchanges.

After the participation of the computing problem, parallel computing techniques are required to communicate and coordinate the calculation process. Two different communication models are often used to achieve the communications and coordination of the partitioned computing jobs. These two models are called the distributed memory model and the shared memory model. In the former, each computing core has its own share of memory, whilst in the latter, all computing cores share the same memory field. A good example of the distributed memory model is the Message Passing Interface (MPI) technique whilst Open Multi-Processing (OpenMP) and POSIX threads (pthreads) techniques are good examples of the shared memory model. Regardless of which parallel computing model is used, the coordination and communication tasks are usually assigned to a specific computing core that is often called the master core while all other parallelised computer cores are called the slave cores.

Table 4 Summary of wheel-rail wear models

\begin{tabular}{|c|c|c|c|c|c|c|}
\hline Wear model & KTH & Sheffield & British & Florence & Budapest & Coimbra \\
\hline \multicolumn{7}{|l|}{ Material } \\
\hline Rail & UIC 900A, UIC1100 & UIC 900A & BS11 & UIC60 & BS11 & EN 260 \\
\hline Wheel & $\mathrm{R} 7$ & $\mathrm{R} 8 \mathrm{~T}$ & $\mathrm{R} 8 \mathrm{~T}$ & ORE S1002 & Unknown & $\mathrm{R} 7$ \\
\hline Friction condition & Dry, lubricated & Dry, wet & Dry & Dry & Dry & Dry \\
\hline
\end{tabular}




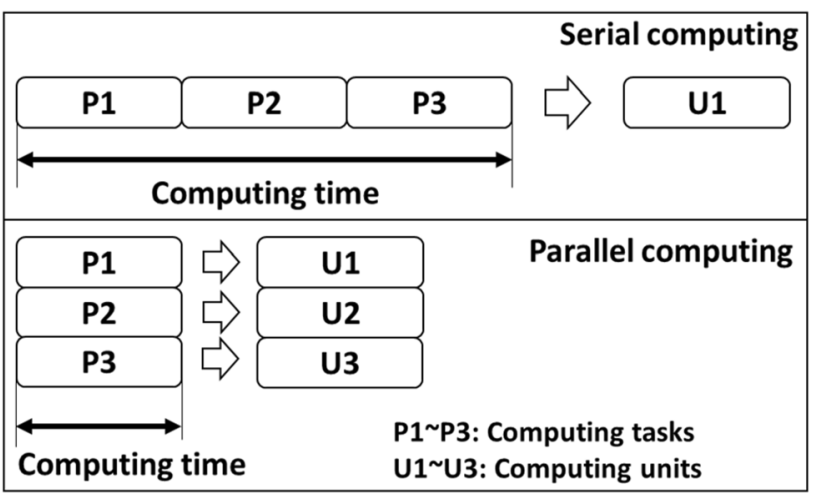

Fig. 15 Parallel and serial computing concepts [24]

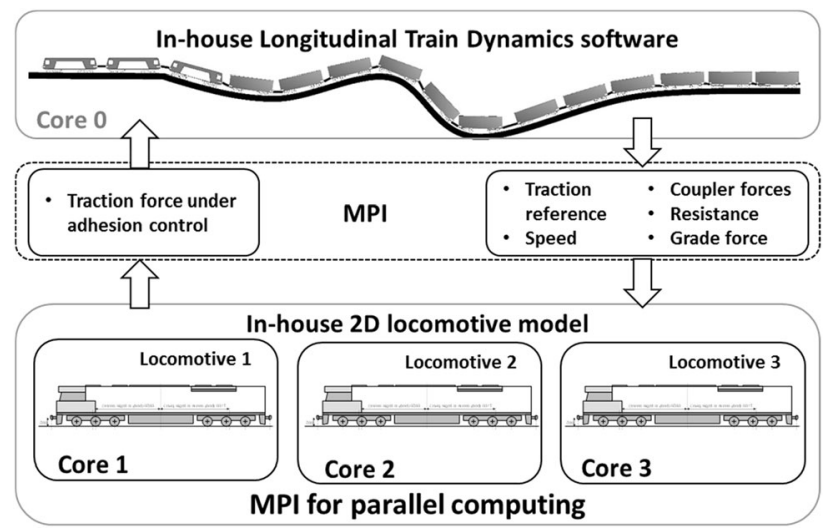

Fig. 16 Parallel computing in locomotive traction studies (MPI) [102]

\subsection{MPI-based parallel co-simulation}

The first case uses a 2D (longitudinal and vertical) locomotive model that considers six wheelsets, two bogie frames and a car body. The locomotive model was used with MPI to study locomotive traction and train dynamics as shown in Fig. 16. Assume that there are $n$ locomotives in the train, then $n+1$ computer cores are recommended to be used. In each calculation step, the train model sends out a series of parameters to individual locomotive models. Among these parameters, one of the most important is the reference value of traction force. This reference is the control command that was generated for train driving from the train model. After receiving the reference values for traction forces, each locomotive model will then proceed to calculate locomotive traction forces with the consideration of wheel-rail adhesion control and various forces in wheelrail contact. The final traction force is the sum or traction forces generated from all wheel-rail contacts of the locomotive model. Having determined the locomotive traction

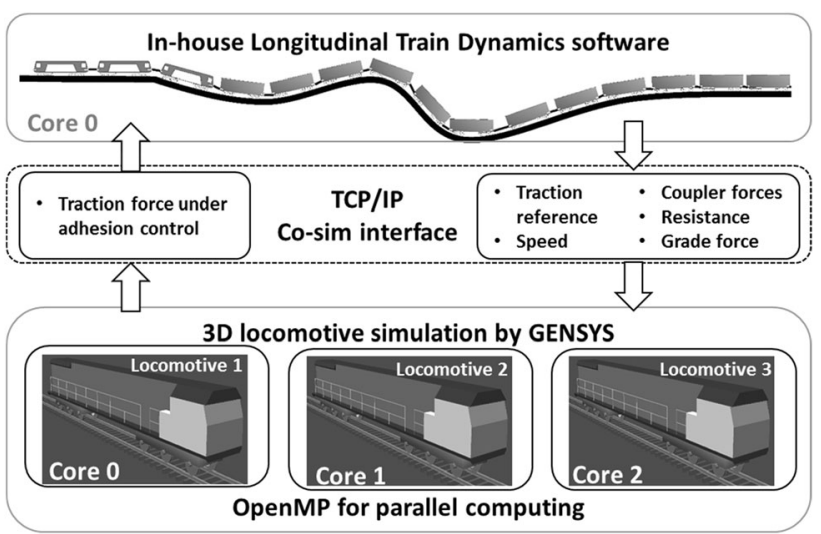

Fig. 17 Parallel computing in locomotive traction studies (OpenMP) [102]

force, it is then sent to the train model to proceed to the next step of simulations.

\subsection{TCP/IP and OpenMP-based parallel co- simulation}

The second case uses a 3D locomotive model developed in GENSYS to study locomotive traction and train dynamics. As shown in Fig. 17, a train dynamics model and a 3D GENSYS locomotive model was connected via a co-simulation interface based on the TCP/IP technique [19]. In this case, the train dynamics model was used as the client whilst GENSYS was used as the host. The co-simulation process is similar to the one in Fig. 16 but has used the TCP/IP technique. Regarding the parallel computing, it is enabled by OpenMP instead of MPI. The utilisation of TCP/IP or OpenMP is due to various reasons: (1) GENSYS is a commercial software package which does not allow recompilation to facilitate the MPI technique, hence the TCP/IP technique was used as it does not require a recompilation of the GENSYS software. (2) Once the TCP/ IP technique is used, synchronisation is not required any more from the parallel computing technique as TCP/IP has the capability of synchronising the computing processes of the train dynamics model and GENSYS. (3) When synchronisation is not required from OpenMP, the programming task is very simple to achieve parallel computing and, in this case, OpenMP's main task is the initiate the simulations of locomotive models on individual computer cores with no changes required for the codes of GENSYS and only five lines required for the codes of the train model; and (4) MPI allows easy information exchange among multiple independent computing tasks whilst, to achieve the same function using OpenMP, is more complicated. The combination of TCP/IP and OpenMP is therefore a good choice as the information change process in this case is taken care by the TCP/IP technique. 


\subsection{Locomotive traction simulations using parallel computing}

Three simulations were conducted to study locomotive traction forces. All simulations have the same track and train configurations. The simulations are: (1) conventional longitudinal train dynamics (LTD) [22] simulations without the consideration of detailed locomotive models as shown in Figs. 16 and 17; (2) parallel computing using MPI and a 2D locomotive model as shown in Fig. 16; and (3) parallel computing using OpenMP and a 3D locomotive model as shown in Fig. 17. The wheel-rail slip limit for models that considered wheel-rail contact was set to be $7 \%$; all simulations have the maximum adhesion limit of 0.35 .

The simulated traction forces for the leading locomotive of the train are presented in Fig. 18. Two significant observations were made from the traction force results. The first observation is that the maximum traction forces simulated by $2 \mathrm{D}$ and $3 \mathrm{D}$ locomotive models on the first tangent track section $(3.15-3.30 \mathrm{~km})$ were evidently smaller than that by the conventional LTD model. Traction forces from the simulations at these two track sections are listed in Table 5. In these results, the adhesion force utilisation was calculated as the ratio of traction force to the maximum adhesion force available. The equivalent adhesion

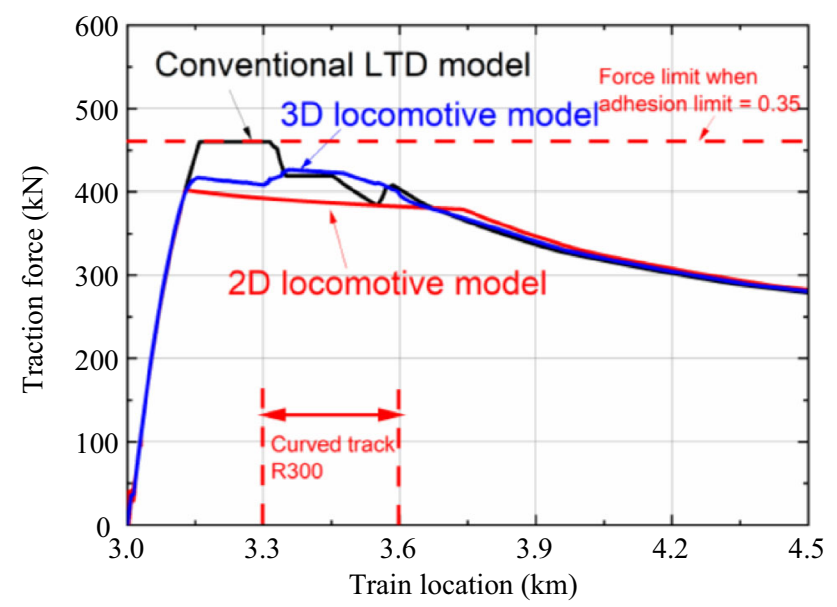

Fig. 18 Simulated traction forces using different models coefficient was calculated as the ratio of traction force to the overall gravitational force due to weight of the locomotive.

The results in Fig. 18 and Table 5 indicate that the traditional traction model (LTD model) assumes that the maximum traction force that can be achieved equals the available maximum adhesion force. However, the simulated maximum traction forces obtained by the advanced models (2D and 3D models) are about $10 \%-5 \%$ lower than for the traditional model (LTD).

The second and more interesting observation that was made from the results in Fig. 18 is that the traction force simulated by the 3D locomotive model slightly increased during curve negotiation. This seems to negate the normal impression that traction forces reduce during curving [102]. Further investigation into the wheel-rail contact has indicated one explanation which shows that, during curve negotiation, two contact points have been detected on both right and left wheels of the first wheelset at different times. Furthermore, evident longitudinal creep forces were generated from the second contact point on the right wheel. The total creep forces generated by the first contact point were decreasing during curve negotiation. However, at the same time, additional creep forces were generated from the second contact point. The force reductions at the first contact points were smaller than the forces generated from the second contact points. This is the reason why the traction forces increased during curve negotiation in Fig. 18.

\section{Design of novel power technologies through advanced locomotive studies}

Increasing fuel prices, scarcity of fossil fuels and the drive for achieving environment friendly technology have led to developing novel power technologies for locomotives. Some of the pros and cons of alternative sources of power for locomotives are listed in [103]. The gas turbine and LNG are old technologies that have potential in reducing NOx emissions but have some disadvantages. Gas turbine

Table 5 Simulated traction forces

\begin{tabular}{lllll}
\hline Location $(\mathrm{km})$ & Model & Traction force $(\mathrm{kN})$ & Adhesion force utilisation $(\%)$ & Equivalent adhesion coefficient \\
\hline 3.15 & LTD & 460 & 100 & 0.350 \\
& 2D & 400 & 87 & 0.305 \\
3D & 416 & 90 & 0.315 \\
3.3 & LTD & 460 & 100 & 0.350 \\
& 2D & 390 & 85 & 0.298 \\
& 3D & 410 & 89 & 0.312 \\
\hline
\end{tabular}


engines are expensive and require specialised maintenance [103]. The LNG engine struggles to match diesel engine power output, is expensive due to mechanical complexity, and also faces challenges of fuel price fluctuations [103]. In the fuel cell technology, hydrocarbon fuels are processed to produce hydrogen fuel that generates DC power for AC traction drives. Fuel cells using hydrogen fuel provide zero emissions. The challenges with hydrogen fuel technology are the alternatives of production of hydrogen fuel onboard, or its storage and distribution. Hydrogen can be stored as compressed gas, cryogenic liquid, and metal hydride.

Hybrid locomotives use forms of DC power sources from alternate energy sources such as battery systems and other energy storage systems. Like fuel technology, the hybrid locomotive faces challenges of battery technologies and the operational principles of energy storage systems.

Advancement in the modelling, simulation and virtual prototyping of locomotive systems now allows investigation of the need for space and weight of the required battery system at the locomotive. Methods of modern computer design techniques on the modelling of hybrid locomotives were discussed in [104, 105].

\subsection{Modelling technique of hybrid locomotives}

A hybrid train operation is considered to provide greater energy efficiency when some of the energy produced by the application of dynamic braking can be reutilised which would otherwise be wasted as heat energy. The idea of using dual-mode locomotives has been considered since the 1970s, with one feasibility study being performed by the US Federal Railroad Administration (FRA) in 1979 [106]. Considering heavy haul train operational scenarios in Australia, heavy haul trains can accommodate a large energy storage system (ESS) which has the potential to allow the use of hybrid technology efficiently. One of the challenges is to operate the ESS at a suitable operational state that allows

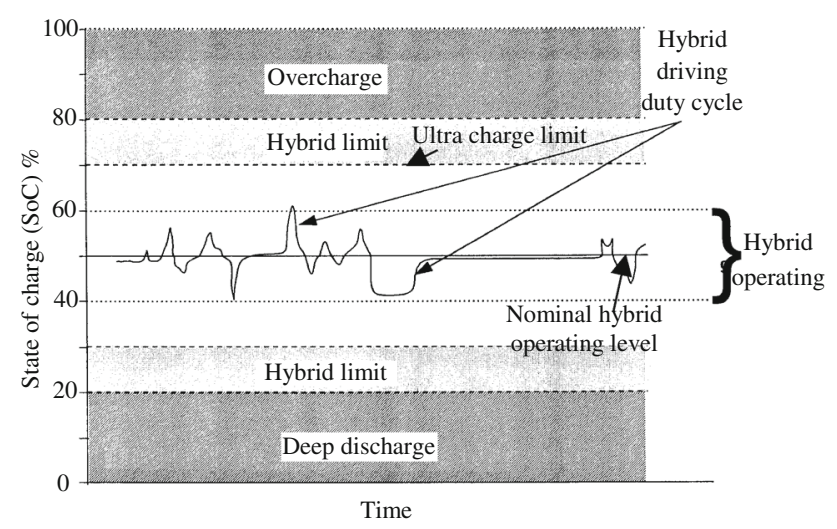

Fig. 19 Recommended state of charge limits for battery operation in hybrid locomotives [107] rapid charging which ensures reliable performances as well as longevity of the equipment. Nelson [107] reported that the battery system should be operated at a nominal $50 \%$ state of charge (SoC) level with the hybrid operations limited between $20 \%$ and $80 \%$ of the full SoC level (Fig. 19).

Hybrid locomotives are assumed as having similar weights to diesel locomotives considering the fact that the battery system mass including inverter should be equal to 50-60 t [108, 109]. An example of design parameters of a hybrid locomotive based on mechanical parameters of a diesel-electric locomotive is shown in Table 6.

\subsection{Using simulation tools to assess locomotive design outcomes}

Advancements in the modelling techniques allow an investigation of the progressive SoC level of a hybrid locomotive at the design stage using techniques developed in $[20,23,110]$. Three simulation environments would need to be used to represent full train operation embedded in the control algorithm of a locomotive. Co-simulation approaches between train and Multibody Simulation (MBS) of the locomotive, and co-simulation between MBS and another program containing a code generating algorithm of the electrical part has been proposed to evaluate the SoC of hybrid locomotives in [104, 105]. Modelling of traction system requires several blocks of models including a model of traction motors, inverters and control algorithms, inverter DC bus and alternator including excitation and rectifier subsystems, and details are available in [111]. The ESS sub-block for the hybrid locomotive uses a lookup table to generate voltage input based on speed and notch positions as discussed in [111]. The voltage parameter is then converted to current and then to power. The power parameter is converted to energy which is integrated by a numerical solver to evaluate the SoC of the hybrid system at every timestep of simulation.

The technique of assessing SoC based on train and locomotive operation leads to the development of a method to further post-process the results of simulations to allow assessing locomotive design outcomes such as the ESS control algorithm and the volume and mass of a battery system. An example method is presented in Fig. 20 to demonstrate the applicability of the advanced simulation technique in assessing a locomotive design. As the method suggests, the first step involves obtaining the data of the railway network including track geometry, train configuration, and operational modes. Step 2 involves modelling the train configuration on the specific track route to obtain the speed and notch information necessary to implement in the MBS model. Step 3 includes developing the MBS model representing the mechanical part of the locomotive that takes inputs from both train simulation and the code 
Table 6 Design characteristics of diesel-electric and hybrid locomotives [108]

\begin{tabular}{|c|c|c|}
\hline General information & Diesel-electric & Hybrid \\
\hline Power type & Diesel-electric & Electric (battery) \\
\hline Wheel arrangement (UIC/AAR) & $\mathrm{C}_{\mathrm{o}}-\mathrm{C}_{\mathrm{o}} / \mathrm{C}-\mathrm{C}$ & $\mathrm{C}_{\mathrm{o}}-\mathrm{C}_{\mathrm{o}} / \mathrm{C}-\mathrm{C}$ \\
\hline \multicolumn{3}{|l|}{ Dimensions (approximately) } \\
\hline Length (mm) & 21,200 & 21,200 \\
\hline Width (mm) & 2950 & 2950 \\
\hline Height $(\mathrm{mm})$ & 4245 & 4245 \\
\hline Locomotive weight (t) & 136.2 & 136.2 \\
\hline Axle load $(\mathrm{t})$ & 22.7 & 22.7 \\
\hline Topology of electric power transmission system & $\mathrm{AC}-\mathrm{DC}-\mathrm{AC}$ & $\mathrm{DC}-\mathrm{AC}$ \\
\hline Wheel diameter $(\mathrm{mm})$ & 1066 & 1066 \\
\hline \multicolumn{3}{|l|}{ Power plant and battery system data } \\
\hline Power output (gross) $(\mathrm{kW})$ & 3356 & - \\
\hline Battery system maximum discharge/charge capacity $(\mathrm{kW})$ & & $3100 / 5000$ \\
\hline Battery system specification (MWh) & & 5 \\
\hline \multicolumn{3}{|l|}{ Performance figures } \\
\hline Traction power $(\mathrm{kW})$ & 3100 & 3100 \\
\hline \multicolumn{3}{|l|}{ Tractive effort } \\
\hline Maximum starting traction effort $(\mathrm{kN})$ & 600 & 600 \\
\hline Maximum continuous traction effort $(\mathrm{kN})$ & 520 & 520 \\
\hline Maximum dynamic braking power $(\mathrm{kW})$ & - & 5000 \\
\hline Maximum dynamic braking effort $(\mathrm{kN})$ & 325 (from 50 to near $0 \mathrm{~km} / \mathrm{h}$ ) & 325 (from 50 to near $0 \mathrm{~km} / \mathrm{h}$ ) \\
\hline
\end{tabular}

generated program. The results from the MBS can be analysed along with the inputs from the electrical model to provide locomotive design outcomes. The electrical part can be modified to suit the proposed battery system which would allow better approximation of the mass and space requirement of the battery system. The information on driving strategy would also be useful to assess the ESS control algorithm.

Wayside charging stations have been considered as an option for hybrid locomotives where continuous electrification on the rail network is not available. The digital twin technique can be applied to assess the location of wayside stations, and example plots (Figs. 21, 22) are added from reference [105]. One case of simulation showed that SoC can be reduced from $100 \%$ to $60 \%$ on the first leg of a journey in the loaded condition which represents a mine to port heavy haul freight transport condition. As $60 \%$ SoC was found sufficient for the return leg of the journey between port and mine in the empty condition, one proposal was to setup a charging station at the mine (case 2, Fig. 22). As an alternative, two further simulation cases were performed (Fig. 22) and it was observed that it would also be possible to install the charging station at the port. Thus, it follows that the simulation tool has good prospects to analyse the different requirements of train and hybrid locomotive operations.

\section{Challenges in the development of locomotive models and digital twins}

There are a great number of major tasks that should be considered in order to deliver an accurate digital twin technology implementation in the locomotive design practice:

- Friction mapping The exact representation of friction conditions in the V-model Stage 3 (see Fig. 2) based on the locomotive position on the track should be implemented in the model. There are a great number of complexities associated with the introduction of the changes in friction conditions into the model. These are associated with the existing friction models having no explicit physical interpretation [72]. Some limited research activities in this area are in progress $[112,113]$. There are almost no research activities in terms of numerical modelling on the distribution of lubricants along the track and across the top of the rail under operational conditions.

- Conformal contact There are a limited number of research activities on the introduction of conformal contact modelling [114-116]. There is no accurate assessment on how different models will influence the prediction results. 


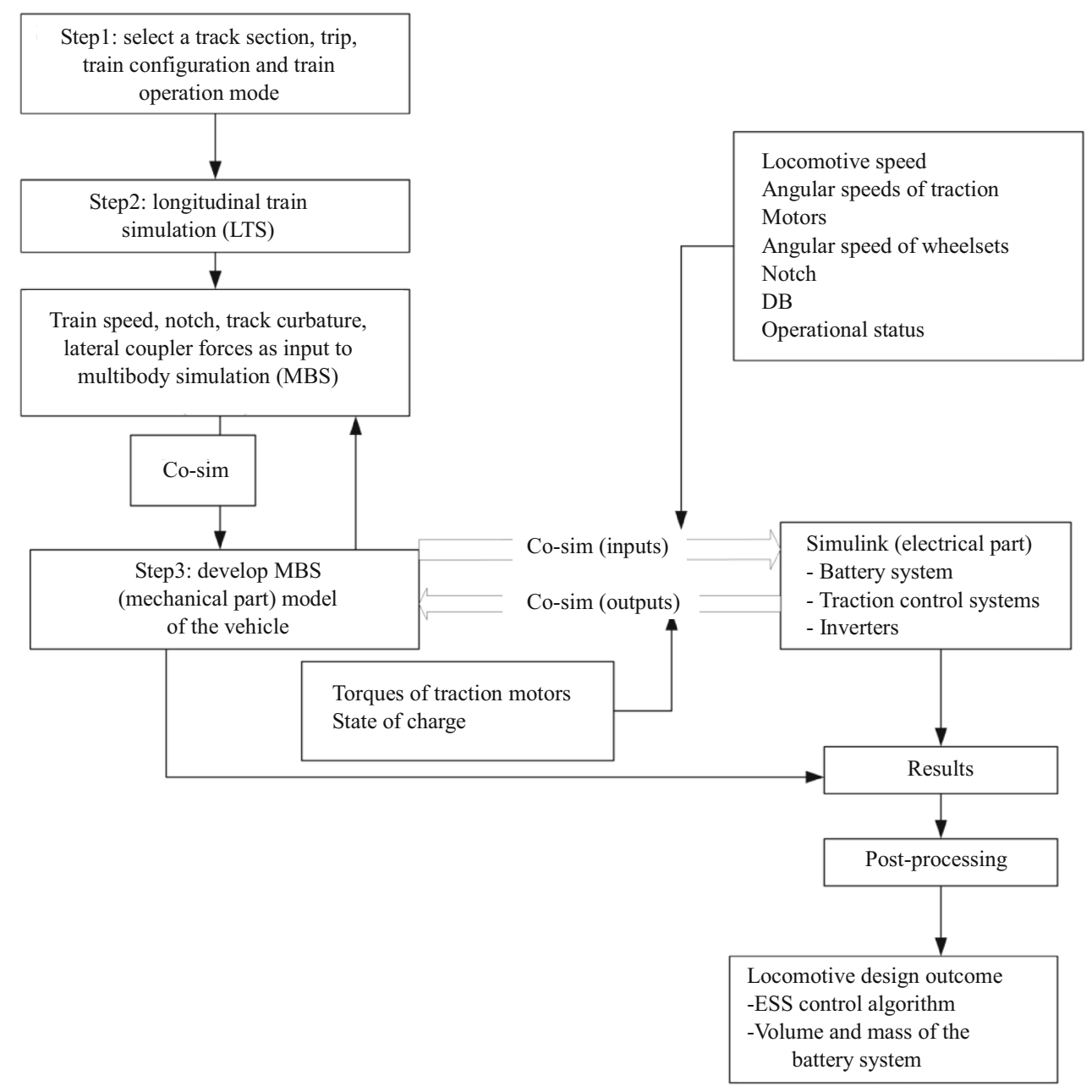

Fig. 20 Method to implement modelling techniques to achieve locomotive design outcomes

- Environmental conditions There are no exact models or studies on how the environmental conditions should be introduced in digital twins. The recent research shows that the weather has a significant influence on the train operational results [117]. It is also necessary to consider other external loads that might act on a locomotive such a wind, wind gusts, etc. There is a question regarding how to connect simulations to the meteorology database and how to use such data in the detailed analysis.

- Wear mapping and RCF Most rail wear models are built on the data delivered for specific wheel and rail materials. Most researchers currently use these models that can be considered as indicators only for possible wear and RCF developments. There are some developments in this area [93]. However, questions exist on how the laboratory measurements should be transferred into a real-world application scenario [118, 119] and how worn wheel and rail profiles should be introduced in the model for long-term track studies, especially, for cases where mixed train operations (for example, passenger and freight) are in progress.

- Train simulations This area progresses very well in terms of the improvements that have recently been made [22]. However, some challenges still exist as part of operational uncertainties. One such challenge relates to train resistance $[120,121]$ and virtual driver modelling issues considering that each train driver uses his own driving strategy. It might not be a problem for unmanned train operations because they are based on predefined algorithms.

- Software implementation The continuing improvement in computer technology requires development of more capable algorithms for co-simulation and parallel computing tasks considering that the $\mathrm{V}$-model described in this paper is a multidisciplinary-based model.

All these challenges show that there is space for further improvement in the digital twin development area and the consolidation of efforts from experts in different areas is needed. 

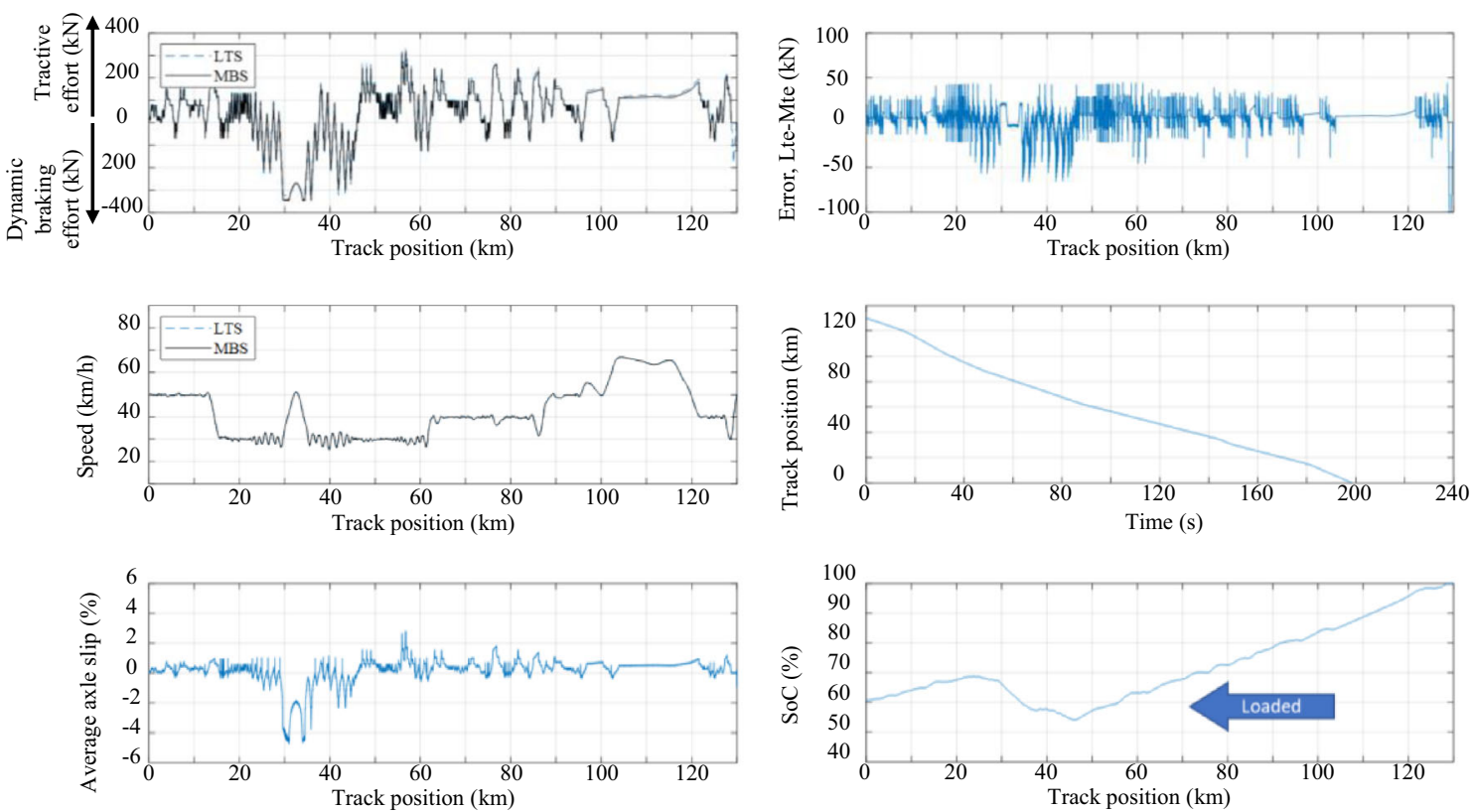

Fig. 21 Trip 1 leg 1, the loaded train travels from mine to port (starting at the fully charged condition) [105]

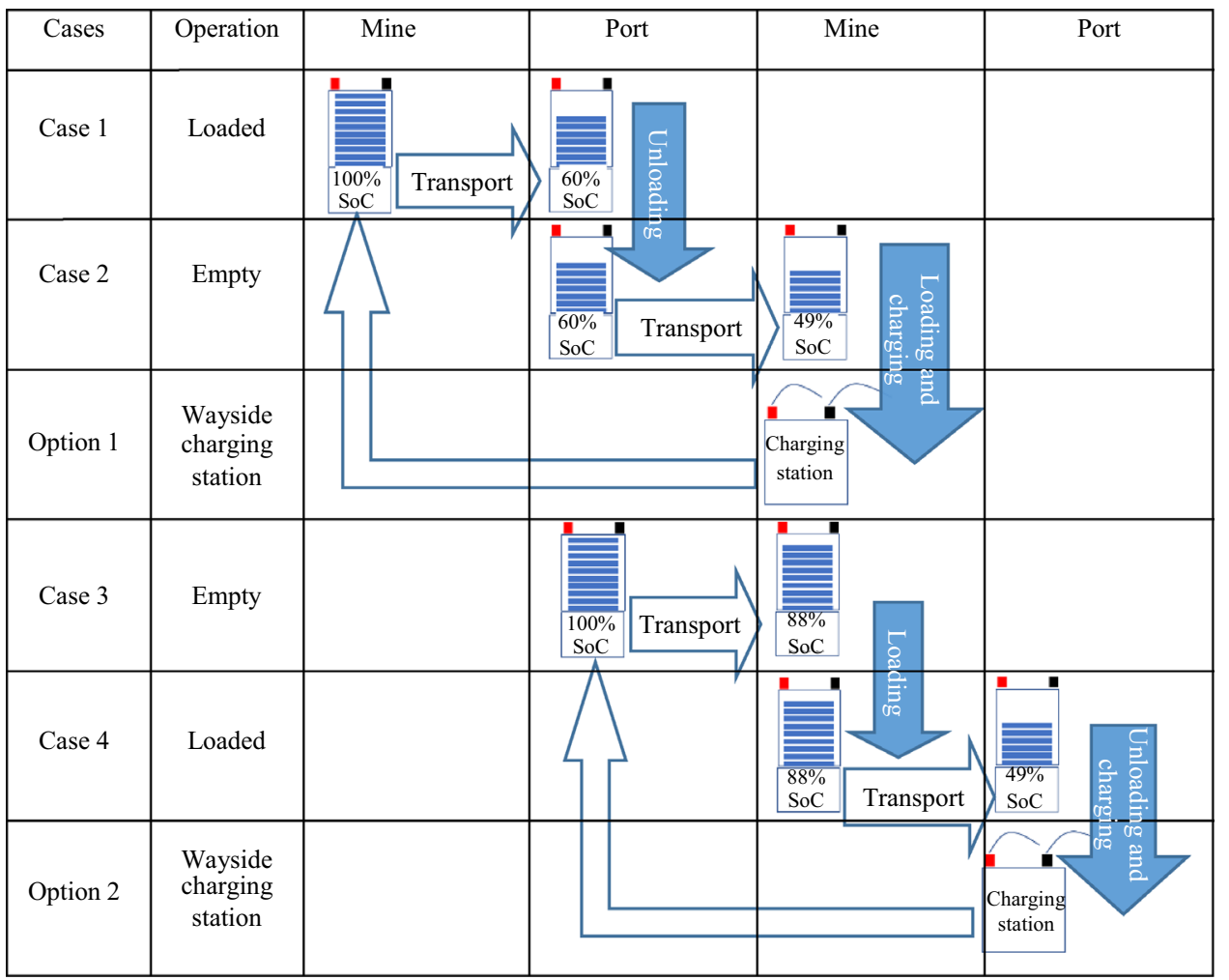

Fig. 22 Positions of wayside charging stations [105] 


\section{Conclusions}

As shown in this paper, the multidisciplinary approach built on the V-model approach widely used in systems engineering has significant implications for improvement of locomotive design techniques and the optimisation of design solutions by means of the application of advanced computational methods and their implementation on highperformance computing clusters.

The existing major challenges in the development of locomotive models and digital twins have been summarised but they still do not guarantee the delivery of accurate results due to the presence of a great number of uncertainties. From the overall perspective, there is significant room for future improvements in locomotive traction science including the application of new power sources in locomotive design solutions.

The near future requires some specific research to be conducted on the friction and wear field and laboratory measurement methodologies in terms of the transition from scaled to full scale problems. This would improve the understanding of locomotive dynamics and its response to the traction and braking modes.

Future work includes the continuation of further digital twin theory development and its application to create an extended performance specification for an optimal locomotive design that will satisfy both rollingstock and railway infrastructure owners and to contribute to the improvements of maintenance and operational safety procedures.

Acknowledgements Dr. Qing $\mathrm{Wu}$ is the recipient of an Australian Research Council Discovery Early Career Award (Project No. DE210100273) funded by the Australian Government.

Open Access This article is licensed under a Creative Commons Attribution 4.0 International License, which permits use, sharing, adaptation, distribution and reproduction in any medium or format, as long as you give appropriate credit to the original author(s) and the source, provide a link to the Creative Commons licence, and indicate if changes were made. The images or other third party material in this article are included in the article's Creative Commons licence, unless indicated otherwise in a credit line to the material. If material is not included in the article's Creative Commons licence and your intended use is not permitted by statutory regulation or exceeds the permitted use, you will need to obtain permission directly from the copyright holder. To view a copy of this licence, visit http://creativecommons. org/licenses/by/4.0/.

\section{References}

1. Thorburn J, Haywood G (2008) The use of train performance simulation in the development of locomotive concepts. In: Proceedings of conference on railway engineering (CORE
2008). Railway Technical Society of Australasia, Perth, WA, Australia, 7-10 September 2008, pp 369-376

2. McCabe D (2008) Standard locomotive. In: Proceedings of AusRAIL 2010, Australasian Railway Association, Perth, WA, Australia, 23-24 November 2010, pp 1-6

3. Cole C, Spiryagin M, Sun YQ, Vo KD, Tieu KA, Zhu HT (2014) R3.119-locomotive adhesion. Final Report, CRC for Rail Innovation, Brisbane, Australia

4. Vo KD, Tieu KA, Zhu HT, Kosasih PB (2015) Comparisons of stress, heat and wear generated by AC versus DC locomotives under diverse operational conditions. Wear 328-329:186-196

5. Vo KD, Tieu KA, Zhu HT, Kosasih PB (2015) The influence of high temperature due to high adhesion condition on rail damage. Wear 330-331:571-580

6. Ahmad S, Nielsen D, Wu Q, Spiryagin M (2020) Final reporttrack structures vs train dynamics and load effects-stage II. WP7, Version 1.3, Australasian Centre for Railway Innovation, Canberra

7. Spiryagin M, Persson I, Hayman M, Wu Q, Sun Y, Nielsen D, Bosomworth C, Cole C (2019) Friction measurement and creep force modelling methodology for locomotive track damage studies. Wear 432-433:1-16

8. Graessler I, Hentze J, Bruckmann T (2018) V-models for interdisciplinary systems engineering. In: Marjanović D, Štorga M, Škec S, Bojčetić N, Pavković N (eds) 15th International design conference of proceedings of the DESIGN 2018. University of Zagreb, Dubrovnik, Croatia, 21-24 May 2018, pp 747-756

9. Gausemeier J, Moehringer S (2003) New guideline VDI 2206: a flexible procedure model for the design of mechatronic systems. In: Folkeson A, Gralen K, Norell M, Sellgren U (eds) Proceedings of 14th international conference on engineering design (ICED 03). The Design Society, UK. Stockholm, Sweden, 19-21 August 2003

10. Wright L, Davidson S (2020) How to tell the difference between a model and a digital twin. Adv Model Simul Eng Sci 7(13):1-13

11. West T, Blackburn M (2017) Is digital thread/digital twin affordable? A systemic assessment of the cost of DoD's latest Manhattan project. Procedia Comput Sci 114:47-56

12. Defense Acquisition University. Digital twin. DAU glossary of defense acquisition acronyms and terms. https://www.dau.edu/ glossary/Pages/Glossary.aspx\#!bothD27349. Accessed 8 June 2021

13. Spiryagin M, Wolfs P, Cole C, Spiryagin V, Sun Y, McSweeney T (2017) Design and simulation of heavy haul locomotives and trains. Ground vehicle engineering series. CRC Press, Boca Raton

14. Polach O, Berg M, Iwnicki S (2020) Simulation of railway vehicle dynamics. In: Iwnicki $S$, Spiryagin $M$, Cole $C$, Mcsweeney T (eds) Handbook of railway vehicle dynamics, 2nd edn. CRC Press, Boca Raton, pp 651-722

15. Spiryagin M, George A, Sun Y, Cole C, McSweeney T, Simson S (2013) Investigation of locomotive multibody modelling issues and results assessment based on the locomotive model acceptance procedure. Proc Inst Mech Eng Part F J Rail Rapid Transit 227(5):453-468

16. Polach O, Böttcher A, Vannuci D et al (2015) Validation of simulation models in the context of railway vehicle acceptance. Proc Inst Mech Eng Part F J Rail Rapid Transit 229(6):729-754

17. Götz G, Polach O (2018) Verification and validation of simulations in a rail vehicle certification context. Int J Rail Transp $6(2): 83-10$

18. Juris M (2019) Shift2Rail-PLASA2. Deliverable D 4.1. Virtual Certification: State of the art, gap analysis and barriers 
identification, benefits for the Rail Industry. Report H2020S2RJU-CFM-2018

19. Spiryagin M, Simson S, Cole C, Persson I (2012) Co-simulation of a mechatronic system using Gensys and Simulink. Veh Syst Dyn 50(3):495-507

20. Spiryagin M, Wolfs P, Szanto F, Cole C (2015) Simplified and advanced modelling of traction control systems of heavy-haul locomotives. Veh Syst Dyn 53(5):672-691

21. Spiryagin M, Wolfs P, Cole C, Stichel S, Berg M, Plöchl M (2017) Influence of AC system design on the realisation of tractive efforts by high adhesion locomotives. Veh Syst Dyn 55(8):1241-1264

22. Cole C, Spiryagin M, Wu Q, Sun YQ (2017) Modelling, simulation and applications of longitudinal train dynamics. Veh Syst Dyn 55(10):1498-1571

23. Spiryagin M, Persson I, Wu Q, Bosomworth C, Wolfs P, Cole C (2019) A co-simulation approach for heavy haul long distance locomotive-track simulation studies. Veh Syst Dyn 57(9):1363-1380

24. Wu Q, Spiryagin M, Cole C, McSweeney T (2020) Parallel computing in railway research. Int J Rail Transp 8(2):111-134

25. Wu Q, Spiryagin M, Sun Y, Cole C (2021) Parallel co-simulation of locomotive wheel wear and rolling contact fatigue in a heavy haul train operational environment. Proc Inst Mech Eng Part F J Rail Rapid Transit 235(2):166-178

26. Polach O, Evans J (2013) Simulations of running dynamics for vehicle acceptance: application and validation. Int $\mathrm{J}$ Railw Technol 2(4):59-84

27. Spiryagin M, Cole C, Sun Y, McClanachan M, Spiryagin V, McSweeney T (2014) Design and simulation of rail vehicles. CRC Press, Boca Raton, Ground vehicle engineering series

28. Rail Industry Safety \& Standards Board (RISSB). AS 7509:2017 Rolling stock-dynamic behaviour. Brisbane, Australia

29. Iwnicki S (1998) Manchester benchmarks for rail vehicle simulation. Veh Syst Dyn 30(3-4):295-313

30. European Committee for Standardisation, EN 14363 (2019-11) Railway applications-Testing for the acceptance of running characteristics of railway vehicles-Testing of running behaviour and stationary tests

31. UIC 518:2009. Testing and approval of railway vehicles from the point of view of their dynamic behaviour-safety-track fatigue-ride quality. Paris, France

32. Szanto F (2017) Do we need more standards? In: Proceedings of AusRAIL PLUS 2017, Rail's Digital Revolution, Brisbane, Australia, 21-23 November 2017, pp 1-3

33. Hiensch M, Steenbergen M (2018) Rolling contact fatigue on premium rail grades: damage function development from field data. Wear 394-395:187-194

34. Tian Y, Daniel WJT, Liu S, Meehan PA (2015) Comparison of PI and fuzzy logic based sliding mode locomotive creep controls with change of rail-wheel contact conditions. Int J Rail Transp $3(1): 40-59$

35. Liu S, Tian Y, Daniel WJT, Meehan PA (2017) Dynamic response of a locomotive with $\mathrm{AC}$ electric drives to changes in friction conditions. Proc Inst Mech Eng Part F J Rail Rapid Transit 231(1):90-103

36. Tian Y (2015) Locomotive traction and rail wear control. Dissertation, University of Queensland

37. Spiryagin V (2004) Improvement of dynamic interaction between the locomotive and railway track. Dissertation, East Ukrainian National University (in Russian)

38. Simson S, Cole C (2008) Parametric simulation study of traction curving of three axle steering bogie designs. Veh Syst Dyn 46(1):717-728
39. Spiryagin M, Cole C, Sun YQ (2014) Adhesion estimation and its implementation for traction control of locomotives. Int J Rail Transp 2(3): 187-204

40. Casanueva C, Enblom R, Stichel S, Berg M (2017) On integrated wheel and track damage prediction using vehicle-track dynamic simulations. Proc Inst Mech Eng Part F J Rail Rapid Transit 231(7):775-785

41. Zhou Z, Chen Z, Spiryagin M, Bernal Arango E, Wolfs P, Cole C, Zhai W (2021) Dynamic response feature of electromechanical coupled drive subsystem in a locomotive excited by wheel flat. Eng Fail Anal 122:105248

42. DEsolver, GENSYS Reference Manual. http://gensys.se/ref_ man.html. Accessed 27 May 2021

43. Kragelsky IV, Dobychin MN, Kombalov VS (1982) Friction and wear calculation methods. Pergamon Press, Oxford

44. Descartes S, Desrayaud C, Niccolini E et al (2005) Presence and role of the third body in a wheel-rail contact. Wear 258(7-8):1081-1090

45. Lewis R, Dwyer-Joyce RS, Lewis SR et al (2012) Tribology of the wheel-rail contact: the effect of third body materials. Int J Railw Technol 1(1):167-194

46. Spiryagin M, Lee KS, Yoo HH et al (2008) Modeling of adhesion for railway vehicles. J Adhes Sci Technol 22(10-11):1017-1034

47. Shrestha S, Spiryagin M, Wu Q. Variable control setting to enhance rail vehicle braking safety. In: Proceedings of 2020 Joint Rail Conference, American Society of Mechanical Engineers, St. Louis, MO, USA, paper V001T09A001

48. Magel E (2017) A survey of wheel/rail friction. Federal Railroad Administration, Office of Research, Development, and Technology, Washington, DC, USA, Report No.: DOT/FRA/ORD17-21

49. Khalladi A, Elleuch K (2017) Tribological behavior of wheelrail contact under different contaminants using pin-on-disk methodology. J Tribol 139(1):011102

50. Zhu Y, Olofsson U, Chen H (2013) Friction between wheel and rail: a pin-on-disc study of environmental conditions and iron oxides. Tribol Lett 52:327-339

51. Galas R, Smejkal D, Omasta M et al (2014) Twin-disc experimental device for study of adhesion in wheel-rail contact. Eng Mech 21(5):329-334

52. Gallardo-Hernandez EA, Lewis R (2008) Twin disc assessment of wheel/rail adhesion. Wear 265(9-10):1309-1316

53. Bosso N, Zampieri N (2014) Experimental and numerical simulation of wheel-rail adhesion and wear using a scaled roller rig and a real-time contact code. Shock Vib. Article ID 385018: $1-14$

54. Shrestha S, Spiryagin M, Wu Q (2019) Friction condition characterization for rail vehicle advanced braking system. Mech Syst Signal Process 134:106324

55. Allen PD, Zhang W, Liang Y et al (2019) Roller rigs. In: Iwnicki S, Spiryagin M, Cole C, Mcsweeney T (eds) Handbook of railway vehicle dynamics, 2nd edn. CRC Press, Boca Raton, pp 761-823

56. Matsumoto A, Sato Y, Ohno H et al (2008) A new measuring method of wheel-rail contact forces and related considerations. Wear 265(9-10):1518-1525

57. Palinko M (2016) Estimation of wheel-rail friction at vehicle certification measurements. Dissertation, KTH Royal Institute of Technology

58. Spiryagin M, Persson I, Hayman M et al (2019) Friction measurement and creep force modelling methodology for locomotive track damage studies. Wear 432-433:202932

59. Harrison H (2008) The development of a low creep regime, hand-operated tribometer. Wear 265(9-10):1526-1531 
60. Polach O (2005) Creep forces in simulations of traction vehicles running on adhesion limit. Wear 258(7-8):992-1000

61. Schlunegger H (1989) Haftwertausnützung für die Entwicklung der Zugkräfte. ZEV-Glasers Annalen 6-7:194-203

62. Logston CF, Itami GS (1980) Locomotive friction-creep studies. J Eng Ind 102(3):275-281

63. Yuan Z, Wu M, Tian C et al (2021) A review on the application of friction models in wheel-rail adhesion calculation. Urban Rail Transit 7(1):1-11

64. Andersson S (2009) Friction and wear simulation of the wheelrail interface. In: Lewis R, Olofsson U (eds) Wheel-rail interface handbook. Woodhead Publishing, CRC, Cambridge, pp 93-124

65. Croft BE, Vollebregt EAH, Thompson DJ (2012) An investigation of velocity-dependent friction in wheel-rail rolling contact. In: Maeda $\mathrm{T}$ et al (eds) Noise and vibration mitigation for rail transportation systems. Notes on numerical fluid mechanics and multidisciplinary design, vol 118. Springer, Tokyo, pp 33-41

66. Vollebregt EAH (2015) FASTSIM with falling friction and friction memory. In: Nielsen $\mathrm{J}$ et al (eds) Noise and vibration mitigation for rail transportation systems. Notes on numerical fluid mechanics and multidisciplinary design, vol 126. Springer, Berlin, pp 425-432

67. Chen HC (1997) On the rolling contact of high speed wheel/rail system. Dissertation, Academy of Railway Sciences of China, Beijing

68. Zhang W, Chen J, Wu X et al (2002) Wheel/rail adhesion and analysis by using full scale roller rig. Wear 253(1-2):82-88

69. Vollebregt EAH, Schuttelaars HM (2012) Quasi-static analysis of two-dimensional rolling contact with slip-velocity dependent friction. J Sound Vib 331(9):2141-2155

70. Croft B, Jones C, Thompson D (2011) Velocity-dependent friction in a model of wheel-rail rolling contact and wear. Veh Syst Dyn 49(11):1791-1802

71. Polach O (2001) Influence of locomotive tractive effort on the forces between wheel and rail. Veh Syst Dyn Suppl 35(Sup.):7-22

72. Spiryagin M, Polach O, Cole C (2013) Creep force modelling for rail traction vehicles based on the Fastsim algorithm. Veh Syst Dyn 51(11):1765-1783

73. Piotrowski J (2010) Kalker's algorithm Fastsim solves tangential contact problems with slip-dependent friction and friction anisotropy. Veh Syst Dyn 48(7):869-889

74. Yang Z, Deng X, Li Z (2019) Numerical modeling of dynamic frictional rolling contact with an explicit finite element method. Tribol Int 129:214-231

75. Hertz H (1881) Über die Berührung fester elastischer Körper. J fur die Reine und Angew Math 92:156-171

76. Kalker JJ (1982) A fast algorithm for the simplified theory of rolling contact. Veh Syst Dyn 11(1):1-13

77. Piotrowski J, Kik W (2008) A simplified model of wheel/rail contact mechanics for non-Hertzian problems and its application in rail vehicle dynamic simulations. Veh Syst Dyn 46(1-2):27-48

78. Sichani MS, Enblom R, Berg M (2014) A novel method to model wheel-rail normal contact in vehicle dynamics simulation. Veh Syst Dyn 52(12):1752-1764

79. Ayasse J, Chollet H (2005) Determination of the wheel rail contact patch in semi-Hertzian conditions. Veh Syst Dyn 43(3):161-172

80. Linder C (1997) Verschleiss von Eisenbahnrädern mit Unrundheiten.Dissertation. ETH Nr. 12, ETH Zurich

81. Vollebregt EAH (2020) User guide for CONTACT, rolling and sliding contact with friction. Vtech $\mathrm{CMCC}$, Technical report 20-01, version 21.1. https://www.cmcc.nl/documentation
82. Sichani MS, Enblom R, Berg M (2016) An alternative to Fastsim for tangential solution of the wheel-rail contact. Veh Syst Dyn 54(6):748-764

83. Kalker JJ (1996) Book of tables for the Hertzian creep-force law. Delft University of Technology, Delft

84. Kalker JJ (1990) Three-dimensional elastic bodies in rolling contact. Kluwer Academic Publishers, Dordrecht

85. Vollebregt EAH (2014) Numerical modeling of measured railway creep versus creep-force curves with CONTACT. Wear 314(1-2):87-95

86. van der Wekken CD, Vollebregt EAH (2018) Local plasticity modelling and its influence on wheel-rail friction. In: Z Li, A Nunez (ed) Proceedings of the 11th international conference on contact mechanics and wear of rail/wheel systems. Delft University of Technology, Delft, Netherlands, pp 1013-1018

87. Shrestha S, Wu Q, Spiryagin M (2018) Wheel-rail contact modelling for real-time adhesion estimation systems with consideration of bogie dynamics. In: Li Z, Núñez A (eds) 11th International conference on contact mechanics and wear of rail/ wheel systems, Delft, The Netherlands, pp 862-869

88. Spiryagin M, Vollebregt E, Hayman M, Persson I, Wu Q, Bosomworth C, Cole C (2020) Development and computational performance improvement of the wheel-rail coupling for heavy haul locomotive traction studies. Veh Syst Dyn. https://doi.org/ 10.1080/00423114.2020.1803371

89. Olofsson U, Telliskivi T (2003) Wear, plastic deformation and friction of two rail steels: a full-scale test and a laboratory study. Wear 254(1-2):80-93

90. Jendel T (2002) Prediction of wheel profile wear-comparisons with field measurements. Wear 253(1-2):89-99

91. Lewis R, Dwyer-Joyce RS (2004) Wear mechanisms and transitions in railway wheel steels. Proc Inst Mech Eng Part J Eng Tribol 218(6):467-478

92. Lewis R, Olofsson U (2004) Mapping rail wear regimes and transitions. Wear 257(7-8):721-729

93. Lewis R, Magel E, Wang W-J et al (2017) Towards a standard approach for the wear testing of wheel and rail materials. Proc Inst Mech Eng Part F J Rail Rapid Transit 231(7):760-774

94. Pearce TG, Sherratt ND (1991) Prediction of wheel profile wear. Wear 144(1-2):343-351

95. Dearden J (1960) The wear of steel rails and tyres in railway service. Wear 3:43-59

96. Ignesti M, Malvezzi M, Marini L et al (2012) Development of a wear model for the prediction of wheel and rail profile evolution in railway systems. Wear 284-285:1-17

97. Auciello J, Ignesti M, Malvezzi M et al (2012) Development and validation of a wear model for the analysis of the wheel profile evolution in railway vehicles. Veh Syst Dyn 50(11):1707-1734

98. Ignesti M, Innocenti A, Marini L et al (2014) Development of a model for the simultaneous analysis of wheel and rail wear in railway systems. Multibody Syst Dyn 31:191-240

99. Zobory I (1997) Prediction of wheel/rail profile wear. Veh Syst Dyn 28(2-3):221-259

100. Ramalho A (2015) Wear modelling in rail-wheel contact. Wear 330-331:524-532

101. Ye Y, Sun Y, Shi D et al (2021) A wheel wear prediction model of non-Hertzian wheel-rail contact considering wheelset yaw: comparison between simulated and field test results. Wear 474-475:203715

102. Wu Q, Spiryagin M, Wolfs P, Cole C (2019) Traction modelling in train dynamics. Proc Inst Mech Eng Part F J Rail Rapid Transit 233(4):382-395

103. Semple JD (2007) The next generation of locomotive power. In: Proceedings of the AusRAIL Plus Conference, 4-6 December 2007, Sydney, Australia 
104. Ahmad S, Spiryagin M, Wu Q, Wolfs P, Bosomworth C, Cole C (2021) Rapid charging train operational concepts for hybrid heavy haul locomotive consists. In: Proceedings of the conference on railway excellence, 21-23 June 2021, Perth, Australia

105. Ahmad S, Spiryagin M, Cole C, Wu Q, Wolfs P, Bosomworth C (2021) Analysis of positioning of wayside charging stations for hybrid locomotive consists in heavy haul train operations. Rail Eng Sci 29(3):285-298

106. Lawson LJ, Cook LM (1979) Wayside energy storage study: volume IV - dual mode locomotive: preliminary design study. US Department of Transportation, Federal Railroad Administration, Washington, DC

107. Nelson RF (2000) Power requirements for batteries in hybrid electric vehicles. J Power Sour 91(1):2-26

108. Spiryagin M, Wolfs P, Wu Q, Cole C, McSweeney T, Bosomworth C (2020) Rapid charging energy storage system for a hybrid freight locomotive. In: Proceedings of the 2020 ASME joint rail conference, 19-22 April 2020, St. Louis, MO

109. Spiryagin M, Bruni S, Bosomworth C, Wolfs P, Cole C (2021) Rail vehicle mechatronics. CRC Press, Boca Raton

110. Spiryagin M, Wu Q, Bosomworth C, Cole C, Wolfs P, Hayman $M$ et al (2019) Understanding the impact of high traction hybrid locomotive designs on heavy haul train performance. In: Proceedings of the AusRAIL PLUS conference, 3-5 December 2019, Sydney, Australia

111. Spiryagin M, Wu Q, Wolfs P, Sun Y, Cole C (2018) Comparison of locomotive energy storage systems for heavy-haul operation. Int J Rail Transp 6(1):1-15

112. Evans M, Skipper WA, Buckley-Johnstone L, Meierhofer A, Six $\mathrm{K}$, Lewis R (2021) The development of a high pressure torsion test methodology for simulating wheel/rail contacts. Tribol Int $156: 106842$

113. Six K, Meierhofer A, Muller G et al (2015) Physical processes in wheel-rail contact and its implications on vehicle-track interaction. Veh Syst Dyn 53(5):635-650

114. Meymand SZ, Keylin A, Ahmadian M (2016) A survey of wheel-rail contact models for rail vehicles. Veh Syst Dyn 54(3):386-428

115. Vollebregt EAH (2018) Conformal contact: corrections and new results. Veh Syst Dyn 56(10):1622-1632

116. Vollebregt E (2021) Detailed wheel/rail geometry processing with the conformal contact approach. Multibody Syst Dyn 52:135-167

117. Meierhofer A, Trummer G, Bernsteiner C, Six K (2020) Vehicle tests showing how the weather in autumn influences the wheelrail traction characteristics. Proc Inst Mech Eng Part F J Rail Rapid Transit 234(4):426-435

118. Magel E, Kalousek J, Sroba P. (2014) Chasing the magic wear rate. In: Pombo J (ed) Proceedings of the second international conference on railway technology: research, development and maintenance, Paper 116. Civil-Comp Press, Stirlingshire

119. Magel E, Mutton P, Ekberg A, Kapoor A (2016) Rolling contact fatigue, wear and broken rail derailments. Wear 366-367:249-257

120. Wu Q, Wang B, Spiryagin M, Cole C (2020) Curving resistance from wheel-rail interface. Veh Syst Dyn. https://doi.org/10. 1080/00423114.2020.1843689

121. Wu Q, Wang B, Cole C, Spiryagin M (2021) Implications of lateral coupler forces for rail vehicle curving resistance. ASME J Comput Nonlinear Dyn 16(3):031002 